Research Articles: Systems/Circuits

\title{
Time course of activity-dependent changes in auditory nerve synapses reveals multiple underlying cellular mechanisms
}

https://doi.org/10.1523/JNEUROSCI.1583-21.2022

Cite as: J. Neurosci 2022; 10.1523/JNEUROSCI.1583-21.2022

Received: 3 August 2021

Revised: 10 January 2022

Accepted: 28 January 2022

This Early Release article has been peer-reviewed and accepted, but has not been through the composition and copyediting processes. The final version may differ slightly in style or formatting and will contain links to any extended data.

Alerts: Sign up at www.jneurosci.org/alerts to receive customized email alerts when the fully formatted version of this article is published.

Copyright (@ 2022 Wong and Xu-Friedman

This is an open-access article distributed under the terms of the Creative Commons Attribution 4.0 International license, which permits unrestricted use, distribution and reproduction in any medium provided that the original work is properly attributed. 
Time course of activity-dependent changes in auditory nerve synapses reveals multiple underlying

4 Abbreviated title: Time course of synaptic changes at endbulbs

$5 \quad$ Nicole F. Wong and Matthew A. Xu-Friedman*

6 Department of Biological Sciences, University at Buffalo, State University of New York, Buffalo, New York

$7 \quad 14260$

$8 \quad *$ Corresponding author address: Dept. Biological Sciences, University at Buffalo, State University of New

9 York, Buffalo, NY 14260. E-mail: mx@buffalo.edu

11 Number of pages: 30

12 Number of figures: 8

13 Number of tables, multimedia, 3D models: 0

14 Number of words in Abstract ( $\leq 250): 241$

15 Number of words in Significance Statement ( $\leq 120)$ : 118

16 Number of words in Introduction ( $\leq 650)$ : 570

17 Number of words in Discussion ( $\leq 1500)$ : 1371

18 Conflict of Interest: Authors declare no conflict of interest.

Acknowledgements: We thank S. Brongo, C. Cook, A. Gennaro, K. Nguyen, T. Ngodup, G. Si, J. Puskas,

21 and X. Zhuang for comments and support throughout this project. We thank V. Gellatly and J. Engel for maintaining the mouse colony, F. Wang at Duke University for the generous gift of the AVIL-CRE mice, 
advice. This work was supported by funding from the National Institute of Deafness and Other Communication Disorders of the National Institutes of Health (RO1 DC015508).

\section{Abstract}

Abnormal levels of acoustic activity can result in hearing problems such as tinnitus and language processing disorders, but the underlying cellular and synaptic changes triggered by abnormal activity are not well understood. To address this issue, we studied the time course of activity-dependent changes that occur at auditory nerve synapses in mice of both sexes after noise exposure and conductive hearing loss. We found that EPSC amplitude and synaptic depression decreased within two days of noise exposure, through a decrease in the probability of vesicle release $\left(P_{r}\right)$. This was followed by a gradual increase in EPSC amplitude, through a larger pool of releasable vesicles $(N)$. Occlusion of the ear canal led to a rapid decrease in EPSC amplitude, through a decrease in $N$, which was followed by an increase in EPSC amplitude and synaptic depression through an increase in $P_{\mathrm{r}}$. After returning to normal sound levels, synaptic depression recovered to control levels within 1 to $2 \mathrm{~d}$. However, repeated exposure to noise for as little as $8 \mathrm{hr} / \mathrm{d}$ caused synaptic changes after $7 \mathrm{~d}$, suggesting recovery did not fully offset changes. Thus, there appear to be three activity-dependent mechanisms in auditory nerve synapses: bidirectional changes in $P_{\mathrm{r}}$ in 1 to $2 \mathrm{~d}$, slower bidirectional changes in $N$ through synaptic growth or retraction, and rapid down-regulation of $N$ with low activity. The dynamic changes indicate that multiple mechanisms are present to fine-tune synaptic fidelity across different acoustic conditions in a simple relay.

\section{Significance}

Hearing Impairments can arise from exposure to noise or conductive hearing loss. This appears to result from changes in the brain, but the mechanisms are not well understood. We study this issue by 
studying the synapses made by auditory nerve fibers called endbulbs of Held. These synapses undergo bidirectional changes in size and release probability of neurotransmitters in response to increased or decreased activity. Here we made a close examination of how quickly these synaptic characteristics change, which indicates there are at least three cellular mechanisms underlying changes. Furthermore, repeated exposure to brief periods of noise can produce cumulative effects. These changes could significantly affect hearing, especially since they occur at the start of the central auditory pathway.

\section{Introduction}

Acoustic experience can influence the transmission of information throughout the auditory pathway (Rubio, 2020; Walmsley et al., 2006). Increased activity, such as resulting from exposure to loud noise, can lead to tinnitus (Shore and Wu, 2019). Decreased activity, such as occurs during otitis media, can result in language processing disorders (Holm and Kunze, 1969; Whitton and Polley, 2011). These hearing deficits are caused by changes in the central auditory pathway (Sanes and Bao, 2009). It is important to identify the cellular processes involved in activity-dependent synaptic changes to develop prevention and treatment strategies. It is also important to understand the time course of the effects, so that therapeutic interventions can be made before hearing is permanently affected.

Synaptic changes can come about through changes in the size of the readily releasable pool of vesicles $(N)$, the probability of vesicle release $\left(P_{r}\right)$, or the quantal size $(Q)$. There is extensive evidence in multiple systems that $N, P_{\mathrm{r}}$, and $Q$ can change in response to activity in vitro (Castillo, 2012; Davis, 2006; Luscher et al., 2000; Turrigiano, 2012). These synaptic properties have also been shown to be modulated in vivo (Chen et al., 2011; Hengen et al., 2013; Keck et al., 2013; Knott et al., 2006). In the auditory system, noise exposure and conductive hearing loss can affect $N, P_{r}$, or $Q$ (Grande et al., 2014; Mendoza Schulz et al., 2014; Mowery et al., 2019), but how these different synaptic properties change and how 
quickly changes take place is not well understood. By studying the time course, it may provide information about how many cellular mechanisms are involved.

A useful synapse to study the effects of acoustic experience is the endbulb of Held, which is formed by auditory nerve fibers onto bushy cells (BCs) in the cochlear nucleus (Ryugo and Fekete, 1982; Ryugo and Sento, 1991; Spirou et al., 2005). BCs relay precise timing information to the superior olive (Grothe et al., 2010; Joris et al., 1998; Oertel, 1999), so changes in endbulb function may interfere with sound localization. Endbulbs are sensitive to levels of sound-driven activity, as exposure to nontraumatic levels of noise for a week results in a decrease in $P_{r}$ and an increase in $N$ (Ngodup et al., 2015). The opposite effects, increased $P_{\mathrm{r}}$ and decreased $N$, occur in genetic models of deafness (Mendoza Schulz et al., 2014; Oleskevich et al., 2004), or one week after a bilateral occlusion of the ear canal (Zhuang et al., 2017). Monaural deprivation leads to larger postsynaptic densities, increased AMPA receptor expression, and reduced VGluT1 expression (Clarkson et al., 2016), and the overall effect on $Q$ is unclear. Changes in $P_{\mathrm{r}}$ appear to result from changes in presynaptic calcium influx (Zhuang et al., 2020). A better understanding of the time-course of changes in synaptic properties could provide insight into the number and diversity of activity-dependent mechanisms at endbulbs.

We addressed this issue by assessing $N, P_{r}$, and $Q$ at multiple time points following noise exposure and ear occlusion. We found bidirectional changes in $P_{\mathrm{r}}$ in response to increased or decreased activity with similar time-courses, probably reflecting a single process. By contrast, ear occlusion seemed to result in a rapid down-regulation in $N$, whereas noise exposure led to a slow increase in $N$, suggesting they are initially mediated by different cellular mechanisms. We also found that these mechanisms could be triggered by brief, repeated noise exposure, suggesting they could have significant impact on hearing. 


\section{Materials and Methods}

All experiments were performed with the approval of the University at Buffalo's Institutional Animal Care and Use Committee. Electrophysiology experiments used CBA/CaJ mice (Jackson Labs, stock \#654). Immunohistochemistry experiments were performed on mice expressing YFP in a subset of auditory nerve fibers (see Endbulb structure, below). All experiments utilized mice of either sex ranging in age from postnatal day 20 (P20) to P31.

\section{Noise exposure or ear occlusion}

Mice were primarily housed in facilities with ambient sound levels measuring 21 to $38 \mathrm{~dB}$ SPL (average of $27 \mathrm{~dB}$ ) over a frequency range 1 to $20 \mathrm{kHz}$ as measured by a Larson-Davis 824 sound meter at $1 / 3$ octave intervals. For noise exposure, mice were housed in a separate room, and a speaker (Fostex FT28D) was placed above the cage, and driven by a noise generator (Aco-Pacific 3025). Noise intensities in the cage measured 76 to $85 \mathrm{~dB}$ SPL (average of $81 \mathrm{~dB}$ SPL). Noise exposure was started at P21.

For mice undergoing occlusion, at P21 both ear canals were either surgically ligated or plugged with a silicone elastomer (Kwik-Cast, WPI). Mice undergoing ligation were anesthetized with $200 \mathrm{mg} / \mathrm{kg}$ ketamine plus $10 \mathrm{mg} / \mathrm{kg}$ xylazine. The skin was depilated with Nair, and treated with betadine. An incision was made ventral to the pinna to expose the ear canal, which was ligated with surgical silk (Harvard Apparatus). The incision was closed using suturing and Vetbond. Recovering mice were given carprofen $(5 \mathrm{mg} / \mathrm{kg})$ the following day, and were housed in normal acoustic conditions. Before earplugged mice were used for brain slice electrophysiology or immunohistochemistry, the efficacy of ear plugs was confirmed using auditory brainstem responses (ABRs). Mice with $a<15 \mathrm{~dB}$ shift in $A B R$ threshold were excluded from further study. 


\section{Auditory brainstem responses}

Mice were anesthetized with $200 \mathrm{mg} / \mathrm{kg}$ ketamine plus $10 \mathrm{mg} / \mathrm{kg}$ xylazine and placed on a $37^{\circ} \mathrm{C}$ heating pad (Gaymar) in a sound booth (Med Associates) lined with Sonex sound-attenuating foam (Acoustical Solutions). ABRs were recorded with a vertex electrode, an electrode inserted behind the pinna ipsilateral to the stimulated ear, and a ground electrode inserted contralateral to the stimulated ear. Clicks (100 $\mu \mathrm{s})$ were presented through a speaker (MF1, Tucker-Davis Technologies) placed $10 \mathrm{~cm}$ from the stimulated ear canal driven by a TDT ABR rig powered by a WS4 computer with an R26 processor. ABR threshold was obtained by reducing the stimulus intensity from 90 to $20 \mathrm{~dB}$ SPL in steps of $10 \mathrm{~dB}$, with $5 \mathrm{~dB}$ steps near threshold. $\mathrm{ABR}$ recordings were made and analyzed using BioSig software (Tucker-Davis Technologies Inc.).

\section{Electrophysiology}

To prepare brain slices for electrophysiology, mice were anesthetized with $200 \mathrm{mg} / \mathrm{kg}$ ketamine plus $10 \mathrm{mg} / \mathrm{kg}$ xylazine, then perfused transcardially with ice-cold sucrose solution (in $\mathrm{mM}: 76 \mathrm{NaCl}, 75$ sucrose, $25 \mathrm{NaHCO}_{3}, 25$ glucose, $2.5 \mathrm{KCl}, 1.25 \mathrm{NaH}_{2} \mathrm{PO}_{4}, 7 \mathrm{MgCl}_{2}, 0.5 \mathrm{CaCl}_{2}$ ). Then the brain was removed, and sagittal slices were cut using a Campden Integraslice 7550 MM or a Leica VT1200 (142 $\mu \mathrm{m}$ ), and incubated in standard recording solution (in mM: $125 \mathrm{NaCl}, 26 \mathrm{NaHCO}_{3}, 20$ glucose, $2.5 \mathrm{KCl}, 1.25$ $\mathrm{NaH}_{2} \mathrm{PO}_{4}, 1 \mathrm{MgCl}_{2}, 1.5 \mathrm{CaCl}_{2}$, 4 Na L-lactate, 2 Na-pyruvate, $0.4 \mathrm{Na}$ L-ascorbate, bubbled with $95 \% \mathrm{O}_{2}-5 \%$ $\mathrm{CO}_{2}$ ) at $34^{\circ} \mathrm{C}$ for 20 minutes. Afterwards, slices were kept at room temperature until recordings. During recordings, $1 \mu \mathrm{M}$ strychnine was added to block spontaneous glycinergic IPSCs. Whole-cell voltageclamp recordings were made from BCs in the anteroventral cochlear nucleus (AVCN) using borosilicate patch pipettes of resistance 1.3-2.3 $\mathrm{M} \Omega$. Pipettes were filled with internal solution containing (in $\mathrm{mM}$ ): $35 \mathrm{CsF}, 100 \mathrm{CsCl}, 10 \mathrm{EGTA}, 10 \mathrm{HEPES}$, and $1 \mathrm{QX}-314, \mathrm{pH}$ 7.3, 300 mOsm. BCs were patched under an Olympus BX51WI microscope with a Multiclamp 700B (Molecular Devices) controlled by an ITC-18 
interface (Instrutech), driven by custom-written software (mafPC) running in Igor (WaveMetrics). The bath was perfused at 3-4 ml/min using a pump (403U/VM2; Watson-Marlow), with standard recording solution running through an inline heater to maintain the temperature at $34^{\circ} \mathrm{C}(\mathrm{SH}-27 \mathrm{~B}$ with $\mathrm{TC}-324 \mathrm{~B}$ controller; Warner Instruments). BCs were held at $-70 \mathrm{mV}$ with access resistance 5 to $15 \mathrm{M} \Omega$ compensated to $70 \%$. Cells were identified as BCs by having EPSCs with fast decay kinetics $(\tau<0.2 \mathrm{~ms})$ and half-widths $(<0.5 \mathrm{~ms})$. Single auditory nerve fibers were stimulated using a glass microelectrode placed 30 to $50 \mu \mathrm{m}$ away from the soma with currents of 4 to $20 \mu \mathrm{A}$ through a stimulus isolator (WPI, A360). Single or paired pulses were applied every 8 s. For mean-variance analysis (Fig. 3), the concentration of $\mathrm{CaCl}_{2}: \mathrm{MgCl}_{2}$ was modified to (in $\mathrm{mM}$ ): $1: 2.5,1.5: 1,3: 0.1$, or $4.5: 0.05$.

\section{Endbulb structure}

Endbulb structure was assessed in transgenic mice expressing YFP in auditory nerve fibers.

These mice were generated by crossing mice expressing Cre off a promotor for advillin (AVIL-Cre) (Zhou et al., 2010), with mice derived from Ai32 mice from Jackson Laboratories (strain 024109) that have a floxxed construct of channelrhodopsin-EYFP. Both strains were individually back-crossed into the CBA/CaJ line for over 10 generations before crossing for experiments. In these mice (AVIL-YFP), expression of EYFP is in a subset of auditory nerve fibers, despite widespread expression of advillin in auditory nerve fibers (Hasegawa et al., 2007; Zhang-Hooks et al., 2016). AVIL-YFP mice were anesthetized with $200 \mathrm{mg} / \mathrm{kg}$ ketamine and $10 \mathrm{mg} / \mathrm{kg}$ xylazine, then perfused transcardially with $0.9 \%$ saline followed by $4 \%$ buffered paraformaldehyde. Brains were removed and postfixed (room temperature, $1 \mathrm{hr}$ ) before cryoprotecting in $20 \%$ sucrose $\left(4^{\circ} \mathrm{C}\right)$. Sagittal sections were cut frozen at 25 to $50 \mu \mathrm{m}$ thickness on a sliding microtome (American Optical) and washed in phosphate-buffered saline $(0.9 \% \mathrm{NaCl}, 0.2 \mathrm{M}$ phosphate; PBS, $\mathrm{pH}=7.4)$. Slices were permeabilized with $0.5 \%$ Triton $\mathrm{X}-100$ in PBS (PBST) for 10 min, washed in PBS three times, blocked in 1\% normal goat serum in PBST for $1 \mathrm{hr}$ at room 
temperature, and incubated overnight at $4^{\circ} \mathrm{C}$ in primary antibody solution containing anti-VGluT1 (polyclonal guinea pig, 1:500, Synaptic Systems, \#135304), and anti-GFP (polyclonal rabbit, 1:1000, Invitrogen, A-6455) in PBST. Specificity of the anti-VGluT1 antibody was validated by Synaptic Systems using western blot in VGluT1-knockout animals (see Synaptic Systems website). Specificity of the antiGFP antibody was verified by the absence of auditory nerve labelling in animals that lacked the transgene in auditory nerve fibers (data not shown). The sections were then washed three times in PBS and incubated for $2 \mathrm{hr}$ with secondary antibodies Alexa 488 goat anti-rabbit (1:250, Invitrogen, A-11008) and Alexa 594 goat anti-guinea pig (1:250, Invitrogen, A-11076).

Immunostained sections were imaged on a Leica TCS SP8 confocal microscope system installed on a Leica DMi8 inverted stand. Stacks of images were obtained at $0.3 \mu \mathrm{m}$ interval, and imported into Wavemetrics Igor. Structures were traced with a custom-written program based on Reconstruct (Fiala, 2005). Tracing was done blind to the acoustic experience of the animal.

\section{Experimental design and statistical analysis}

Average results are reported throughout as mean \pm standard error of the mean (SEM) and the number of cells per group is indicated in the text. Because of the variability in endbulb properties, 15 to 20 cells were needed for most measurements. Before statistical comparison, normality was evaluated for each dataset using Shapiro-Wilks tests. Most experiments assessed synaptic features at multiple time points. We first used ANOVA (parametric) or Kruskal-Wallis tests (non-parametric) to test for significant changes across all groups, and if significant, we tested the significance of individual time points with post-hoc tests. We did not detect changes with age in control animals, so control data were pooled for greater statistical power. For post-hoc tests comparing multiple experimental groups to a single control, we used the Tamhane-Dunnett (parametric) or Anderson-Darling many-to-one (nonparametric) tests as implemented in R (adManyOneTest and tamhaneDunnettTest in the PMCMRplus 
package). When experimental groups were compared to each other, we used the Anderson-Darling allpairs test (adAllPairsTest). Post-hoc tests used Holm's correction method for multiple comparisons. The significance level was set at $\alpha=0.05$. Exact $p$ values are shown in the corresponding text.

\section{Results}

Synaptic changes after noise exposure and occlusion

We wanted to determine how quickly noise-exposure or ear-occlusion induced changes in synaptic function. EPSCs were recorded from BCs in whole-cell voltage-clamp following electrical stimulation of single presynaptic auditory nerve synapses. To ensure the stimulation of a single synaptic input, we verified that EPSCs were all-or-none near threshold. We first evaluated the stability of synaptic properties between P20 and P31 (Fig. 1B). At these ages, mice are not yet sexually mature, but the properties of endbulbs appear largely stable (Pliss et al., 2009). We confirmed $\mathrm{EPSC}_{1}$ stability first by performing linear regression which yielded a slope of $10 \pm 202 \mathrm{pA} / \mathrm{d}$ (mean \pm standard error of the mean, 146 cells, 39 mice), which was not significantly different from zero ( $p>0.5$, t test), indicating no change in $\mathrm{EPSC}_{1}$ over these ages (Fig. 1B). Second, we assigned EPSCs to 5 age groups (P20-21: $7.7 \pm 1.6$ nA, 22 cells, 5 mice; P22: $6.7 \pm 1.5$ nA, 16 cells, 6 mice; P23: $9.4 \pm 1.9$ nA, 10 cells, 3 mice; P24-26: $9.0 \pm$ $1.3 \mathrm{nA}, 45$ cells, 13 mice; P27-31: $7.4 \pm 0.9 \mathrm{nA}, 53$ cells, 12 mice). We detected no significant difference among these groups (Kruskal-Wallis, $p=0.8$ ). Therefore, we pooled control $\mathrm{EPSC}_{1}$ data for subsequent comparisons ( $8.0 \pm 0.6 \mathrm{nA} ; 146$ cells).

We then manipulated auditory nerve activity by exposing mice to non-traumatic, broadband

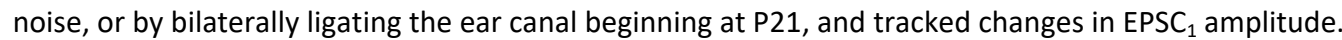
Following noise exposure, EPSC $_{1}$ appeared to decrease between 0.75 to $4 \mathrm{~d}$ compared to control ( $0.25 \mathrm{~d}$ : $7.8 \pm 1.7 \mathrm{nA}, 16$ cells, 7 mice; $0.5 \mathrm{~d}: 7.1 \pm 0.8 \mathrm{nA}, 45$ cells, 6 mice; $0.75 \mathrm{~d}: 4.7 \pm 0.7 \mathrm{nA}, 13$ cells, 3 mice; 1 d: $6.0 \pm 0.6 \mathrm{nA}, 42$ cells, 6 mice; $2 \mathrm{~d}: 4.7 \pm 0.6 \mathrm{nA}, 19$ cells, 4 mice; $3-5 \mathrm{~d}: 5.5 \pm 1.1 \mathrm{nA}, 23$ cells, 9 mice; $6-$ 
$10 \mathrm{~d}: 9.4 \pm 1.1 \mathrm{nA}, 37$ cells, 15 mice) (Fig. 1C, red symbols). EPSC 1 amplitude also appeared to decrease below control between 2-5 d following ear ligation (1 d: $6.8 \pm 0.8 \mathrm{nA}, 36$ cells, 7 mice; $2 \mathrm{~d}: 5.9 \pm 0.8 \mathrm{nA}$, 23 cells, 9 mice; $3-5$ d: $4.3 \pm 0.6$ nA, 30 cells, 8 mice; $6-10$ d: $8.8 \pm 1.1 \mathrm{nA}, 35$ cells, 9 mice) (Fig. $1 \mathrm{C}$, blue circles).

We compared the noise-exposed and ear-ligated groups against control and found there was a significant difference (Kruskal-Wallis, $p<0.001$ ). Post-hoc comparisons indicated only one condition that differed significantly from control, at 3-5 d following ligation ( $p=0.01$ Anderson-Darling many-toone test). We were concerned that the highly conservative corrections for multiple comparisons coupled with the large variance in $\mathrm{EPSC}_{1}$ amplitude might obscure real changes following noise exposure or ear ligation. We had found previously that $N$ increases and $P_{\mathrm{r}}$ decreases following noise exposure, while $N$ decreases and $P_{\mathrm{r}}$ increases following ear ligation, with no detectable changes in $Q$ (Ngodup et al., 2015; Zhuang et al., 2017). We were interested to determine if $N$ and $P_{r}$ might change with different time courses, so we analyzed the noise-exposure and ear-ligated data using regression with two linear segments:

$$
\operatorname{EPSC}(t)=\left\{\begin{array}{rr}
A+B_{1} t, & t<t_{0} \\
A+B_{2}\left(t-t_{0}\right)+B_{1} t_{0}, & t \geq t_{0}
\end{array}\right.
$$

where $A$ is the amplitude of EPSC $C_{1}$ before the manipulation (i.e. $8.0 \mathrm{nA}$ ), $B_{1}$ and $B_{2}$ are the rates with which two processes affect EPSC 1 amplitude, with each process dominating before or after time $t_{0}$. For EPSCs after noise exposure, the fit yielded $t_{0}=1.5 \pm 0.5 \mathrm{~d}, B_{1}=-2.3 \mathrm{nA} / \mathrm{d}$ and $B_{2}=0.5 \pm 0.1 \mathrm{nA} / \mathrm{d}$, with both $B_{1}$ and $B_{2}$ highly significantly different from zero ( $p<0.001$, t test, 195 cells, red line in Fig. 1C). This indicates that $\mathrm{EPSC}_{1}$ amplitude decreases rapidly immediately after noise exposure, and returns to control levels more slowly after several days. For ear ligation, the fit yielded $t_{0}=3.8 \pm 0.7 \mathrm{~d}, B_{1}=-1.1 \pm$ $0.4 \mathrm{nA} / \mathrm{d}$ and $B_{2}=1.4 \pm 0.4 \mathrm{nA} / \mathrm{d}$, with both $B_{1}$ and $B_{2}$ highly significantly different from zero $(p<0.01, \mathrm{t}$ test, 124 cells, blue line in Fig. 1C). This indicates that EPSC amplitude also decreases following ear ligation, but more slowly, and then returns to control levels beginning around 4 days. 
To understand the cellular mechanisms underlying these processes, we wanted to specifically characterize changes in $N, P_{\mathrm{r}}$, and $Q$. We assessed $P_{\mathrm{r}}$ by eliciting pairs of EPSCs with an interval of $3 \mathrm{~ms}$, and calculating the ratio of the EPSC amplitudes (paired-pulse ratio, $P P R=E P S C_{2} / E P S C_{1}$ ) (Fig. $\left.1 \mathrm{~A}\right)$. $P P R$ is sensitive to changes in $P_{\mathrm{r}}$, where an increase in $P_{\mathrm{r}}$ is reflected as a lower PPR, and a decrease in $P_{\mathrm{r}}$ is reflected as a higher PPR. We first examined the stability of PPR in control mice. Linear regression of PPR from P20 to P31 had a slope of $-0.0026 \pm 0.0044$ /d, which was not significantly different from zero ( $p=0.56,146$ cells, 39 mice), indicating no change in PPR over these ages (Fig. 1D). Furthermore, there were no significant changes in average PPR across the age groups (P20-21: $0.56 \pm 0.04,22$ cells, 5 mice; P22: $0.53 \pm 0.04,16$ cells, 6 mice; P23: $0.58 \pm 0.04,10$ cells, 3 mice; P24-26: $0.48 \pm 0.02,45$ cells, 13 mice; P27-31: $0.54 \pm 0.02,53$ cells, 12 mice; ANOVA, $p=0.13$ ) (Fig. 1D). Therefore, control PPR was pooled across all age groups in subsequent analyses $(0.53 \pm 0.01,146$ cells $)$.

Next, we recorded PPR from mice exposed to noise or with ear ligation for up to $13 \mathrm{~d}$ (Fig. 1A, E, red and blue markers $)$. We fit each set of data to an exponential function: $f(t)=y_{\text {start }}+\left(y_{\text {end }}-y_{\text {start }}\right)(1-$ $\left.e^{-t / \tau}\right)$, where $y_{\text {start }}$ is the PPR before manipulation (i.e. 0.53), $y_{\text {end }}$ is the ending PPR, and $\tau$ is the time constant. Following noise exposure, the PPR increased with $\tau=1.07 \pm 0.58 \mathrm{~d}$ and $y_{\text {end }}=0.68 \pm 0.03(160$ cells, Fig. 1E, red line), and following ear ligation, PPR decreased with $\tau=1.97 \pm 1.12 \mathrm{~d}$ and $y_{\text {end }}=0.40 \pm$ 0.03 (124 cells, Fig. 1E, blue line). Analysis with ANOVA indicated that PPR differed significantly following noise exposure and ear ligation $(p<0.001)$. Post-hoc analysis identified the specific days showing significant changes. Following noise exposure, PPR increased significantly beginning at $1 \mathrm{~d}$ and reached a plateau thereafter ( $1 \mathrm{~d}: 0.65 \pm 0.03,33$ cells, 7 mice; $2 \mathrm{~d}: 0.63 \pm 0.03,19$ cells, 3 mice; 3 to 5 d: $0.68 \pm 0.05,23$ cells, 8 mice; 6 to $13 \mathrm{~d}: 0.70 \pm 0.05,22$ cells, 9 mice; $p<0.05$ each group, TamhaneDunnett's test). By contrast, following ear ligation, PPR decreased significantly after $2 \mathrm{~d}$ and reached a plateau thereafter ( $2 \mathrm{~d}$ : $0.45 \pm 0.02,23$ cells, 4 mice; $3-5 \mathrm{~d}: 0.38 \pm 0.02,30$ cells, 7 mice; $6-10 \mathrm{~d}: 0.42 \pm$ 0.02, 35 cells, 5 mice; $p<0.03$ each group, Tamhane-Dunnett test). 
Thus, noise exposure leads to a decrease in $P_{\mathrm{r}}$ within $1 \mathrm{~d}$, consistent with the initial decrease in EPSC $_{1}$. Because $P_{\mathrm{r}}$ remains low, it does not appear likely to explain the subsequent return of EPSC $C_{1}$ to control levels, indicating that other synaptic changes must be taking place, such as increases in $Q$ or $N$. Even more strikingly, ear ligation leads to an increase in $P_{\mathrm{r}}$ within $2 \mathrm{~d}$, but $\mathrm{EPSC}_{1}$ decreases at that time, suggesting the increase in $P_{\mathrm{r}}$ is more than offset by other synaptic changes, such as decreases in $Q$ or $N$. The increase in $P_{r}$ could contribute to the slower increase in EPSC $_{1}$ observed $4 \mathrm{~d}$ after ligation.

\section{Quantal size and frequency}

We next assessed changes in quantal size $(Q)$ by recording spontaneous mEPSC amplitude and frequency (Fig. 2A). Previous studies had found no significant changes in mEPSC amplitude or frequency after one week of noise exposure or ear ligation (Ngodup et al., 2015; Zhuang et al., 2017), and we wanted to evaluate whether changes take place on a faster time scale that could contribute to the changes in $\mathrm{EPSC}_{1}$ we observed. We first examined mEPSC frequency and amplitude between P20 to P30 in control endbulbs, and both appeared stable over this age range. Linear regression of mEPSC amplitude had slope of $-1.2 \pm 1.6 \mathrm{pA} / \mathrm{d}$, and mEPSC frequency had slope of $-0.09 \pm 0.28 \mathrm{~s}^{-1} / \mathrm{d}$, neither of which differed significantly from zero (64 cells, 13 mice, both $p>0.4$, t test, Fig. 2B, C). In addition, we grouped mEPSC amplitudes and frequencies according to age ranges P20-22, P24-26, and P28-30, and no significant differences were detected between the groups (P20-22: amplitude $134 \pm 7$ pA, frequency $6.1 \pm 1.7 \mathrm{~s}^{-1}, 19$ cells, 4 mice; P24-26: $125 \pm 8$ pA, $7.1 \pm 1.5 \mathrm{~s}^{-1}, 27$ cells, 5 mice; P28-30: $132 \pm 9$ pA, $5.3 \pm$ $0.8 \mathrm{~s}^{-1}, 18$ cells, 4 mice; Kruskal-Wallis test, $p=0.58$ for both mEPSC amplitude and frequency) (Fig. 2B, C). Therefore, we pooled control measurements across all ages (amplitude $130 \pm 5$ pA; frequency $6.3 \pm$ $\left.0.8 s^{-1}\right)$

We next examined mEPSCs in bushy cells of mice following noise exposure or ear ligation. There were no significant changes in MEPSC amplitude at any time point following the onset of noise or after 
ear ligation (red and blue markers, Fig. 2D, both $p>0.15$, Kruskal-Wallis test). Thus, the effects of noise exposure or ear ligation on $Q$ are minor, and seem unlikely to contribute to the changes in PPR or EPSC observed in Fig. 1.

We also investigated changes in mEPSC frequency, which may be influenced by changes in $N$ and $P_{\mathrm{r}}$ (Burrone et al., 2002; Prange and Murphy, 1999) which might change with different time courses. There were no significant changes in MEPSC frequency after noise exposure for any of the age groups ( $p$ $=0.53$, Kruskal-Wallis). We also fit mEPSC frequency data using segmented regression (see equation above), constraining $A$ to the average rate of controls $\left(6.3 \mathrm{~s}^{-1}\right)$. For noise exposure, the fit yielded $t_{0}=$ $0.49 \pm 0.77 \mathrm{~d}$, and $B_{1}=-3.0 \pm 4.6 \mathrm{~s}^{-1} / \mathrm{d}$, and $B_{2}=0.05 \pm 0.15 \mathrm{~s}^{-1} / \mathrm{d}$. Neither slope was significantly different from zero ( $p>0.5$ both slopes, t test, 141 cells, 16 mice, red line, Fig. 2E), indicating negligible effects of noise exposure on mEPSC frequency.

By contrast, mEPSC frequency changed significantly following ear-ligation ( $p=0.02$, KruskalWallis). The mEPSC frequency appeared to decrease between 1 and $4 \mathrm{~d}$ following ligation, and post-hoc analysis revealed a significant decrease at $2 \mathrm{~d}\left(1 \mathrm{~d}: 4.3 \pm 0.4 \mathrm{~s}^{-1}, 42\right.$ cells, 7 mice, $p=0.79 ; 2 \mathrm{~d}: 3.4 \pm 0.4 \mathrm{~s}^{-}$ 1, 35 cells, 9 mice, $p=0.04 ; 4 \mathrm{~d}: 3.3 \pm 0.4 \mathrm{~s}^{-1}, 31$ cells, 11 mice, $p=0.06 ; 8 \mathrm{~d}: 5.6 \pm 1.1 \mathrm{~s}^{-1}, 33$ cells, 10 mice, $p=0.79$; Anderson-Darling many-to-one test) (Fig. 2E). Segmented regression yielded $t_{0}=1.7 \pm$ $0.5 \mathrm{~d}, B_{1}=-2.0 \pm 0.6 \mathrm{~s}^{-1} / \mathrm{d}$, and $B_{2}=0.4 \pm 0.2 \mathrm{~s}^{-1} / \mathrm{d}$, and both slopes differed significantly from zero (both $p<0.01$, blue line, Fig. 2E). This suggests that after ligation, one process drives a rapid decrease in mEPSC frequency, followed by a slower process by which mEPSC frequency increases beginning around $2 \mathrm{~d} . P_{\mathrm{r}}$ increases slowly during this period (i.e. PPR decreases, Fig. 1E), so the initial decrease in mEPSC frequency most likely reflects a rapid decrease in the number of functional release sites, consistent with the decrease in $\mathrm{EPSC}_{1}$ observed shortly after ear ligation. 


\section{Mean-variance analysis}

To explicitly quantify the effects of sound exposure on $N, P_{\mathrm{r}}$, and $Q$, we used mean-variance analysis. The relationship between the mean $(\mu)$ and variance $\left(\sigma^{2}\right)$ of $\operatorname{EPSC}_{1}$ amplitude can be described by the equation $\sigma^{2}=Q \mu-\left(\mu^{2} / N\right)$, when the extracellular calcium concentration $\left(\mathrm{Ca}_{\mathrm{e}}\right)$ is varied to influence $P_{\mathrm{r}}$ (Foster and Regehr, 2004; Meyer et al., 2001; Silver, 2003). Recording durations permitted three $\mathrm{Ca}_{\mathrm{e}}$ during each experiment, either $1,1.5$, and $3 \mathrm{mM}$ or $1.5,3$, and $4 \mathrm{mM}$. Assessing $N$ and $P_{\mathrm{r}}$ in the context of individual vesicles would require application of a low-affinity antagonist, to prevent receptor saturation and desensitization (Xu-Friedman and Regehr, 2004). However, in preliminary experiments with $2 \mathrm{mM}$ kynurenate, we could not raise $P_{\mathrm{r}}$ high enough to constrain the fit. Therefore, we did not use a low-affinity antagonist in the experiments presented here, so the values of $N, P_{\mathrm{r}}$, and $Q$ do not simply reflect vesicle properties. Figure $3 \mathrm{~A}$ shows an example recording of a $\mathrm{BC}$ from a control animal. Fitting to the equation above yielded $N=63.6$, and $Q=185 \mathrm{pA}$. Using the values of $Q$ and $N$, we calculated release probability $\left(P_{\mathrm{r}}=\mathrm{EPSC}_{1} / Q N\right)$. For the example in Figure $3 \mathrm{~A}, P_{\mathrm{r}}$ in $1.5 \mathrm{Ca}_{\mathrm{e}}$ was 0.22 . On average, control synapses had $N$ of $73 \pm 9, Q$ of $182 \pm 18 \mathrm{pA}$, and $P_{\mathrm{r}}$ of $0.48 \pm 0.03$ in $1.5 \mathrm{Ca}_{\mathrm{e}}$ (33 cells, 13 mice).

We next examined the effects of noise exposure (Fig. 3B-D) and ear ligation (Fig. 3E-G) on $N, P_{r}$, and $Q$. Comparing all groups simultaneously showed there was a significant change in $N(p<0.001$, Kruskal-Wallis test). Post-hoc analysis indicated there was no significant change in $N$ after noise exposure for $1 \mathrm{~d}(75 \pm 12,13$ cells, 3 mice, $p=0.68$, Anderson-Darling many-to-one test; Fig. $3 \mathrm{H})$, but there was a significant increase at $7 \mathrm{~d}(153 \pm 28,16$ cells, 7 mice, $p=0.02$, Anderson-Darling many-toone test; Fig. $3 \mathrm{H}$ ). The effects at $7 \mathrm{~d}$ are similar to findings in a previous study (Ngodup et al., 2015). Thus, noise exposure leads an increase in $N$ between day 1 and 7 , which may contribute to the increase in $\mathrm{EPSC}_{1}$ over this period (Fig. 1C).

We next considered the effects of ear ligation after 2 and $7 d$ with post-hoc analyses. We saw a significant decrease in $N$ at both 2 and $7 d$ ( 2 d: $29 \pm 7,16$ cells, 4 mice, $p=0.003 ; 7 d: 43 \pm 5,20$ cells, 7 
mice, $p=0.04$; Anderson-Darling many-to-one test, Fig. $3 \mathrm{H}$ ). The results at $7 \mathrm{~d}$ are similar to the findings of a previous study (Zhuang et al., 2017). Thus, $N$ decreased by $2 \mathrm{~d}$ after ear ligation, which likely contributed to the initial decrease in $\mathrm{EPSC}_{1}$ (Fig. 1C) and mEPSC frequency (Fig. 2E).

No significant changes were detected in either $P_{\mathrm{r}}$ or $Q$ following noise exposure or ear ligation ( $p$ $>0.50$, Kruskal-Wallis test). The lack of change in $Q$ is consistent with previous studies (Ngodup et al., 2015; Zhuang et al., 2017) and the present measurements of mEPSC amplitude (Fig. 2D). However, the lack of change in $P_{r}$ is unexpected, especially considering the robust changes in PPR in Fig. 1E. One possible reason for this difference is that the value of $P_{\mathrm{r}}$ in mean-variance analysis is derived from EPSC 1 at a single $\mathrm{Ca}_{\mathrm{e}}$, so quantifying $P_{\mathrm{r}}$ may be subject to more error than $Q$ and $N$, that are produced by fitting over multiple data points. Overall, it seems most likely that after noise exposure, $P_{\mathrm{r}}$ decreases followed by a slower increase in $N$, whereas after ear ligation $N$ initially decreases followed by an increase in $P_{\mathrm{r}}$, with neither manipulation causing a change in $Q$.

\section{Changes in endbulb structure}

The changes in $N$ following noise exposure or ear ligation likely result from changes in the number of release sites. We wanted to see if there were corresponding anatomical changes in endbulb structure. Our strategy was to label endbulbs using an antibody against VGluT1 (Lauer et al., 2013), which reveals puncta surrounding BC somata (Fig. 4A, yellow). VGluT1 labels synaptic vesicles in endbulbs, so we considered VGluT1-positive puncta as likely functional synaptic regions of the endbulb. BCs in mice receive 2 to 5 endbulbs (Cao and Oertel, 2010; Chanda and Xu-Friedman, 2010b; Nicol and Walmsley, 2002; Wang and Manis, 2008). To aid reconstruction of individual endbulbs, we used a strain of mice expressing YFP in a subset of auditory nerve fibers (AVIL-YFP), such that one or two endbulbs were labelled per BC (Fig. 4A, cyan). To ensure that the expression of YFP did not affect the size of the synapse, we compared the areas of YFP-positive and -negative fibers, and found that they were not 
significantly different (YFP-positive: $47.47 \pm 7.09 \mu \mathrm{m}^{3}, 23$ endbulbs; YFP-negative: $39.78 \pm 5.60 \mu \mathrm{m}^{3}, 22$ endbulbs; 3 mice; $p=0.40$, t-test). The expression of YFP did not appear to correlate with calretinin immunolabelling (data not shown), so it is probably unrelated to auditory nerve fiber subtype. We used the YFP labeling to aid in identifying puncta from the same endbulb. VGluT1-positive structures were traced and linked between optical sections (Fig. 4B). The areas of traces were used to calculate the volumes of synaptic regions of each endbulb.

We performed reconstructions of endbulbs from age-matched control, noise-exposed, and earligated mice. Tracing was done blind to the manipulation. A Kruskal-Wallis test found that there was a significant difference between the groups $(p<0.001)$. Post-hoc analysis revealed that there was no significant change in VGlut1 ${ }^{+}$regions of endbulbs after $3 \mathrm{~d}$ of noise exposure compared to P24 controls (control: $38.4 \pm 5.2 \mu \mathrm{m}^{3}, 32$ endbulbs, 3 mice; noise-exposed: $40.9 \pm 4.2 \mu \mathrm{m}^{3}, 48$ endbulbs, 3 mice; $p$ > 0.50, Anderson-Darling all-pairs test) (Fig. 4C). However, VGlut $1^{+}$regions were significantly larger in mice exposed to noise for $7 \mathrm{~d}$ compared to P28 controls (control: $43.0 \pm 4.4 \mu \mathrm{m}^{3}, 50$ endbulbs, 3 mice; noiseexposed: $63.5 \pm 8.1 \mu \mathrm{m}^{3}$, 54 endbulbs, 3 mice; $p=0.02$, Anderson-Darling all-pairs test, Fig. 4C). For ear ligation, VGlut ${ }^{+}$regions of endbulbs were not significantly different after $2 \mathrm{~d}\left(35.5 \pm 4.9 \mu \mathrm{m}^{3}, 24\right.$ endbulbs, 3 mice, $p>0.50$, Anderson-Darling all-pairs test), but were significantly smaller after $7 \mathrm{~d}$ of ear ligation (21.5 $\pm 1.7 \mu \mathrm{m}^{3}$, 59 endbulbs, 3 mice, $p<0.001$, Anderson-Darling all-pairs test, Fig. 4C). These data suggest that elevated or decreased acoustic activity causes morphological changes in the extent of the vesicle pool in the endbulb, not immediately, but after several days.

The slow increase in the extent of the vesicle pool following noise exposure could correspond to the gradual increase in $\mathrm{EPSC}_{1}$ amplitude (Fig. 1C), and the increase in $N$ in mean-variance analysis (Fig. $3 \mathrm{H})$. However, the slow decrease in vesicle pool area following ear ligation does not directly match the faster time course of the decrease in $\mathrm{EPSC}_{1}$ (Fig. 1C), mEPSC frequency (Fig. 2E), or $N$ in mean-variance 
analysis (Fig. 3H). Thus ear ligation appears to trigger another mechanism that drives a decrease in $N$, distinct from large-scale changes in morphology.

\section{Occluding with ear plugs}

We wanted to study the rate of recovery of $P_{\mathrm{r}}$ after returning to normal sound conditions. We were concerned that repeated surgery and anesthesia associated with ligating and un-ligating the ear might obscure changes in $P_{\mathrm{r}}$. Therefore, we evaluated the effectiveness of occlusion by plugging the ear canals with a fast-setting silicone, which could be applied and removed without anesthesia or surgery. We compared the effectiveness of plugging vs. ligating by comparing ABRs to click stimuli. A KruskalWallis test showed that there was a significant difference in ABR threshold between groups $(p<0.001)$. Subsequent post-hoc tests indicated that ABR thresholds increased significantly from $35.5 \pm 1.1 \mathrm{~dB} S P L$ (11 ears, 6 mice) to $57.5 \pm 2.5 \mathrm{~dB}$ SPL after ear-plugging (8 ears, 4 mice, $p<0.001$, Anderson-Darling allpairs test), and to $69.5 \pm 2.9 \mathrm{~dB}$ SPL after ear-ligating (21 ears, 11 mice, $p<0.001$, Anderson-Darling allpairs test) (Fig. 5A, B). Furthermore, while ear plugs were effective, they were significantly less effective at increasing ABR threshold than ligating $(p<0.001$, Anderson-Darling all-pairs test).

We verified whether ear-plugging could induce synaptic changes, by quantifying changes in PPR.

Ear-ligation and ear-plugging had broadly similar effects on PPR, and they were not significantly different at any of the comparable time points (ear-plugging $1 \mathrm{~d}$ : $0.53 \pm 0.02,15$ cells, 3 mice; $2 \mathrm{~d}$ : $0.43 \pm$ 0.03, 13 cells, 3 mice; 4 d: $0.41 \pm 0.03,21$ cells, 3 mice; $8 \mathrm{~d}: 0.42 \pm 0.04,8$ cells, 3 mice; all $p>0.50$, ttests comparing corresponding ear-ligation time points; Fig. 5C). Thus, the effects of ear-plugging and ligation seem similar, and may be useful for studying recovery from occlusion. 
Recovery of $P_{r}$

We explored the recovery of PPR following a return to normal sound conditions after 3 or $10 \mathrm{~d}$ of noise exposure. A Kruskal-Wallis test indicated significant differences in PPR between the different exposure groups $(p=0.001)$. We then conducted post-hoc comparisons using the Anderson-Darling many-to-one test to identify specific differences. For $3 \mathrm{~d}$ of noise exposure, PPR remained significantly elevated by $6 \mathrm{hr}$ in quiet conditions $(0.76 \pm 0.03,9$ cells, 3 mice, $p<0.001)$, and was indistinguishable from control levels beginning at $12 \mathrm{hr}(12 \mathrm{~h}: 0.57 \pm 0.04,7$ cells, 2 mice; $24 \mathrm{hr}: 0.54 \pm 0.06,12$ cells, 3 mice; 36 hr: $0.57 \pm 0.05,15$ cells, 4 mice; $p>0.50$ each test; Fig. $6 \mathrm{~A}$, red circles). For mice exposed to noise for $10 \mathrm{~d}$, a Kruskal-Wallis test also indicated significant differences between groups $(p=0.001)$. Post-hoc analysis using Anderson-Darling many-to-one tests showed that PPR remained significantly elevated after $12 \mathrm{hr}$ in quiet conditions $(0.78 \pm 0.04,19$ cells, 2 mice, $p<0.001)$, slightly elevated above control over the following $24 \mathrm{hr}(1 \mathrm{~d}$ : $0.64 \pm 0.06,14$ cells, 2 mice, $p=0.049)$, and was indistinguishable from control after $1.5 \mathrm{~d}(0.61 \pm 0.04,16$ cells, 4 mice; $p=0.13$; Fig. $6 \mathrm{~A}$, purple circles). This suggests that $P_{\mathrm{r}}$ recovers quickly, with the rate depending on the duration of noise exposure.

We also studied the recovery of PPR after ear-plugging for $3 \mathrm{~d}$. The Kruskal-Wallis test indicated that there were significant differences between the treatment groups $(p=0.009)$. Post-hoc analysis using the Anderson-Darling many-to-one test indicated that PPR was significantly more depressed than control $6 \mathrm{hr}$ and $12 \mathrm{hr}$ after unplugging $(6 \mathrm{hr}: 0.40 \pm 0.04,10$ cells, 2 mice, $p=0.04$; $12 \mathrm{hr}: 0.36 \pm 0.07,8$ cells, 2 mice, $p=0.04)$, and was indistinguishable from control by $1 \mathrm{~d}(0.50 \pm 0.03,9$ cells, 2 mice, $p=$ 0.45; Fig. 6B). Thus, $P_{\mathrm{r}}$ appears to recover on a similar time scale following occlusion or noise exposure.

\section{Repeated exposure}

We examined how periods of recovery between repeated bouts of noise exposure might affect auditory nerve synapses by exposing mice to noise for a number of hours per day for $7 \mathrm{~d}$ before slices 
were cut to assess synaptic properties (Fig. 7A). The $0 \mathrm{hr} / \mathrm{d}$ condition (i.e. no noise exposure) had relatively depressed PPR after $7 d(0.53 \pm 0.02,19$ cells, 5 mice), very similar to the control value used throughout, while $24 \mathrm{hr} / \mathrm{d}$ is the same as constant noise for $7 \mathrm{~d}$ or more in Fig. 1. A Kruskal-Wallis test indicated significant differences between groups $(p<0.001)$. Subsequent post-hoc analysis using the Anderson-Darling many-to-one test indicated a significant increase in PPR after $7 \mathrm{~d}$ of noise exposure for $8 \mathrm{hr} / \mathrm{d}(0.65 \pm 0.03,19$ cells, 2 mice, $p=0.02)$, and $12 \mathrm{hr} / \mathrm{d}(0.71 \pm 0.03,27$ cells, 3 mice, $p<0.001)$ compared to $0 \mathrm{hr} / \mathrm{d}$ (Fig. 7B), but no increase in PPR after $4 \mathrm{hr} / \mathrm{d}(0.47 \pm 0.04,15$ cells, 2 mice). By contrast, EPSC $_{1}$ showed no significant changes for any duration of noise exposure $(4 \mathrm{hr} / \mathrm{d}$ : $4.9 \pm 0.9 \mathrm{nA} ; 8$ $\mathrm{hr} / \mathrm{d}: 7.1 \pm 0.8 \mathrm{nA} ; 12 \mathrm{hr} / \mathrm{d}: 7.4 \pm 0.9 \mathrm{nA} ; p=0.23$, Kruskal-Wallis). These results suggest that the effects of even brief noise exposure can accumulate, resulting in changes in $P_{\mathrm{r}}$ within a few days.

\section{Discussion}

We tracked how quickly changes in acoustic environment lead to physiological and anatomical changes in auditory nerve synapses, which revealed multiple activity-dependent processes (Fig. 8). PPR changes after 1 or $2 \mathrm{~d}$ of noise exposure or occlusion, suggesting activity levels act on a single mechanism to bidirectionally regulate release probability $\left(P_{r}\right)$. Occlusion causes a decrease in EPSC amplitude and mEPSC frequency, most likely through a decrease in $N$, with changes in endbulb structure occurring after several days. This suggests that the rapid mechanism acts by disabling release sites, followed by slower structural remodeling. Noise exposure leads to a slow increase in $N$, with physiological and anatomical features changing together, presumably because adding release sites is more complex.

Recovery from noise or occlusion appeared to be very fast. That might suggest that noise exposure followed by equal time for recovery would produce little effect on synaptic function. However, repeated exposure to noise for as little as $8 \mathrm{hr} / \mathrm{d}$ induced changes in PPR. This may have 
implications for people that are exposed daily to loud environments, despite having time for recovery.

Furthermore, it suggests that the cellular mechanisms involved in detecting the activity levels retain some residual activation from one bout of noise exposure to the next.

\section{Changes in $\mathrm{N}$ and $\mathrm{P}_{r}$, but not $\mathrm{Q}$}

This study shows that for manipulations of both noise exposure and occlusion, endbulbs respond by changing the presynaptic properties of $N$ and $P_{\mathrm{r}}$. PPR results show most clearly that $P_{\mathrm{r}}$ is bidirectionally sensitive to activity, with changes becoming evident in 1 or $2 \mathrm{~d}$. It is notable that the changes take longer to develop than presynaptic forms of long-term potentiation and depression (LTP and LTD) in vitro (Malenka and Bear, 2004), which appear otherwise similar. It is possible the cellular mechanisms are actually the same, but that acoustically-driven activity is less effective at triggering changes. Protocols for inducing LTP/LTD in vitro are very refined, and may be more powerful at recruiting induction mechanisms than acoustic stimuli in vivo. This may also explain the somewhat faster rate of change in $P_{r}$ with noise exposure compared to occlusion ( $1.1 \mathrm{vs} .2 .0 \mathrm{~d}$ ), because the increase in activity with noise is likely to be substantial, while the drop-in activity with occlusion is likely to be smaller.

It is more difficult to evaluate changes in $N$ than in $P_{r}$, so we used multiple lines of evidence. For noise-exposure, both mean-variance analysis and VGluT1 immunohistochemistry suggested that noise does not drive an increase in $N$ within $1 \mathrm{~d}$, but does after $7 \mathrm{~d}$. Noise-driven changes in $\mathrm{EPSC}_{1}$ amplitude are more complex. Shortly after the start of noise exposure, EPSC $_{1}$ amplitude decreases, most likely because of a decrease in $P_{\mathrm{r}}$. Then, after $\sim 1.5$ days, EPSC $_{1}$ amplitude begins to increase, most likely from an increase in $N$ (because $Q$ does not change measurably).

The changes in $N$ with occlusion are more complex. Mean-variance analysis and mEPSC frequency suggest $N$ decreases within 2 to 4 days after occlusion, but structural changes in VGluT1 
immunohistochemistry are not visible until $7 \mathrm{~d}$. Remarkably, the overall effect is an initial decrease in EPSC $_{1}$, despite $P_{\mathrm{r}}$ increasing. Taken together, these results suggest that occlusion triggers a rapid downregulation of $N$, with slower increase in $P_{r}$, followed by structural rearrangements that maintain a low $N$. It is striking that the changes in $N$ and $P_{\mathrm{r}}$ compensate almost perfectly for each other, yielding the same average EPSC 1 after $7 \mathrm{~d}$. During noise exposure, first $P_{\mathrm{r}}$ decreases and then $N$ increases, whereas after occlusion, $N$ appears to decrease first followed by increasing $P_{\mathrm{r}}$. This is surprising because EPSC $_{1}$ in vitro represents release from a fully rested and recovered synapse, which auditory nerve synapses are unlikely to be in vivo, especially in the presence of noise. Even so, recruiting additional release sites would also increase the amplitude of chronically-depressed EPSCs, thereby preserving the fidelity of the synapse. In addition, EPSC amplitude would also be expected to affect the timing of postsynaptic spikes, because postsynaptic latency and jitter are sensitive to EPSP amplitude (Chanda and Xu-Friedman, 2010a; Xu-Friedman and Regehr, 2004; Yang and Xu-Friedman, 2009). This is important, because the timing of BC spikes is used for sound localization (Oertel, 1999), so shifts in EPSC amplitude resulting from changes in activity levels during noise exposure or occlusion could disrupt interaural comparisons of sound level or timing. Adjusting $N$ and $P_{\mathrm{r}}$ together may minimize such disruption. Our methods of noise exposure and occlusion did not perturb quantal size (Q). This is striking, because changes in activity do affect $Q$ in other systems both in vitro (Turrigiano et al., 1998; Wierenga et al., 2006) and in vivo (Hengen et al., 2013; Torrado Pacheco et al., 2021; Wu et al., 2021). Furthermore, changes in $Q$ have been observed in the auditory cortex following occlusion in vivo (Mowery et al., 2019). Endbulbs from knockouts of the synaptic protein Bassoon have deeper depression and show increased $Q$ (Mendoza Schulz et al., 2014). In addition, monaural occlusion leads to lower VGluT1 density on endbulb vesicles and more AMPA receptors at BC postsynaptic densities (Clarkson et al., 2016), which could affect $Q$. An increase in $Q$ would be consistent with the homeostatic effect of synaptic scaling. It is not clear why noise exposure or binaural occlusion do not also cause a 
change in $Q$. Insight into this issue may arise with better understanding of the induction mechanisms driving changes in $Q$ at endbulbs.

\section{Cellular mechanisms of changes in $\mathrm{P}_{r}$ and $\mathrm{N}$}

Our results suggest that during noise exposure, $P_{\mathrm{r}}$ decreases before $N$ increases, whereas during occlusion, $N$ decreases before $P_{\mathrm{r}}$ increases. The changes in $P_{\mathrm{r}}$ appear to occur at roughly the same time following a change in acoustic conditions, suggesting increases and decreases share a common activitydependent mechanism. Imaging experiments suggest that changes in $P_{\mathrm{r}}$ at the endbulb and calyx of Held result from modulation of presynaptic calcium influx (Fekete et al., 2019; Zhuang et al., 2020). The time course for changes in $P_{\mathrm{r}}$ was more than a day, which does not put strong constraints on the possible cellular mechanisms. Calcium influx could be modulated through phosphorylation of channels (Catterall and Few, 2008), which can occur much faster than one day. It is possible that in vivo, the signaling pathway is weakly activated, so phosphorylation could occur more slowly. Alternatively, the cellular mechanism may be intrinsically slow, such as requiring gene expression. Indeed, occlusion leads to a shift in calcium channel subtypes driving release at endbulbs (Zhuang et al., 2020), which could require changes in gene expression, although it is possible that different subtypes are already available in a reserve pool of channels.

Our results suggest two different mechanisms regulating $N$, one following occlusion that rapidly down-regulates release sites, and one following noise exposure that slowly upregulates release sites. The slow increase appears to parallel structural changes following noise exposure. It seems reasonable that structural changes and addition of new release sites could take a significant amount of time, for example if vesicles and proteins associated with neurotransmitter release must be generated de novo (Ataman et al., 2008). By contrast, the rapid decrease in $N$ following occlusion could use fast mechanisms such as removing receptors from the postsynaptic density, as occurs in postsynaptic forms 
of LTD (Luscher et al., 2000), producing a rapid decrease in EPSC $_{1}$ amplitude. It would be interesting to determine if the same release sites that are rapidly disabled after occlusion are then gradually removed by structural changes, or if there are larger reworkings of the synapse taking place.

Implications for hearing

Our findings represent a major change in our understanding of the function of auditory nerve synapses. Until recently, endbulbs were thought to be relatively stable synapses, simply relaying precise temporal information about sounds from the cochlea to the superior olive for sound localization. Now we understand that there are multiple processes regulating $N$ and $P_{\mathrm{r}}$ based on activity. We have shown that these forms of long-term synaptic plasticity can be triggered through realistic exposure. Exposure to noise for $8 \mathrm{hr} / \mathrm{d}$ is sufficient to cause changes in synaptic function, despite even longer periods of recovery. Because endbulbs are a major conduit for auditory activity into the brain, changes in these synapses may have a significant effect on hearing.

\section{References}

Ataman, B., Ashley, J., Gorczyca, M., Ramachandran, P., Fouquet, W., Sigrist, S.J., and Budnik, V. (2008). Rapid activity-dependent modifications in synaptic structure and function require bidirectional Wnt signaling. Neuron 57, 705-718.

Burrone, J., O'Byrne, M., and Murthy, V.N. (2002). Multiple forms of synaptic plasticity triggered by selective suppression of activity in individual neurons. Nature 420, 414-418.

Cao, X.J., and Oertel, D. (2010). Auditory nerve fibers excite targets through synapses that vary in convergence, strength, and short-term plasticity. J Neurophysiol 104, 2308-2320.

Castillo, P.E. (2012). Presynaptic LTP and LTD of excitatory and inhibitory synapses. Cold Spring Harb Perspect Biol 4.

Catterall, W.A., and Few, A.P. (2008). Calcium channel regulation and presynaptic plasticity. Neuron 59, 882-901.

Chanda, S., and Xu-Friedman, M.A. (2010a). A low-affinity antagonist reveals saturation and desensitization in mature synapses in the auditory brain stem. J Neurophysiol 103, 1915-1926.

Chanda, S., and Xu-Friedman, M.A. (2010b). Neuromodulation by GABA converts a relay into a coincidence detector. J Neurophysiol 104, 2063-2074.

Chen, X., Leischner, U., Rochefort, N.L., Nelken, I., and Konnerth, A. (2011). Functional mapping of single spines in cortical neurons in vivo. Nature 475, 501-505. 
Clarkson, C., Antunes, F.M., and Rubio, M.E. (2016). Conductive hearing loss has long-lasting structural and molecular effects on presynaptic and postsynaptic structures of auditory nerve synapses in the cochlear nucleus. J Neurosci 36, 10214-10227.

Davis, G.W. (2006). Homeostatic control of neural activity: from phenomenology to molecular design. Annu Rev Neurosci 29, 307-323.

Fekete, A., Nakamura, Y., Yang, Y.M., Herlitze, S., Mark, M.D., DiGregorio, D.A., and Wang, L.Y. (2019). Underpinning heterogeneity in synaptic transmission by presynaptic ensembles of distinct morphological modules. Nat Commun 10, 826.

Fiala, J.C. (2005). Reconstruct: a free editor for serial section microscopy. J Microsc 218, 52-61.

Foster, K.A., and Regehr, W.G. (2004). Variance-mean analysis in the presence of a rapid antagonist indicates vesicle depletion underlies depression at the climbing fiber synapse. Neuron 43, 119-131.

Grande, G., Negandhi, J., Harrison, R.V., and Wang, L.Y. (2014). Remodelling at the calyx of Held-MNTB synapse in mice developing with unilateral conductive hearing loss. J Physiol 592, 1581-1600.

Grothe, B., Pecka, M., and McAlpine, D. (2010). Mechanisms of sound localization in mammals. Physiol Rev 90, 983-1012.

Hasegawa, H., Abbott, S., Han, B.X., Qi, Y., and Wang, F. (2007). Analyzing somatosensory axon projections with the sensory neuron-specific Advillin gene. J Neurosci 27, 14404-14414.

Hengen, K.B., Lambo, M.E., Van Hooser, S.D., Katz, D.B., and Turrigiano, G.G. (2013). Firing rate homeostasis in visual cortex of freely behaving rodents. Neuron $80,335-342$.

Holm, V.A., and Kunze, L.H. (1969). Effect of chronic otitis media on language and speech development. Pediatrics 43, 833-839.

Joris, P.X., Smith, P.H., and Yin, T.C. (1998). Coincidence detection in the auditory system: 50 years after Jeffress. Neuron 21, 1235-1238.

Keck, T., Keller, G.B., Jacobsen, R.I., Eysel, U.T., Bonhoeffer, T., and Hubener, M. (2013). Synaptic scaling and homeostatic plasticity in the mouse visual cortex in vivo. Neuron 80, 327-334.

Knott, G.W., Holtmaat, A., Wilbrecht, L., Welker, E., and Svoboda, K. (2006). Spine growth precedes synapse formation in the adult neocortex in vivo. Nat Neurosci 9, 1117-1124.

Lauer, A.M., Connelly, C.J., Graham, H., and Ryugo, D.K. (2013). Morphological characterization of bushy cells and their inputs in the laboratory mouse (Mus musculus) anteroventral cochlear nucleus. PLoS One 8, e73308.

Luscher, C., Nicoll, R.A., Malenka, R.C., and Muller, D. (2000). Synaptic plasticity and dynamic modulation of the postsynaptic membrane. Nat Neurosci 3, 545-550.

Malenka, R.C., and Bear, M.F. (2004). LTP and LTD: an embarrassment of riches. Neuron 44, 5-21.

Mendoza Schulz, A., Jing, Z., Sanchez Caro, J.M., Wetzel, F., Dresbach, T., Strenzke, N., Wichmann, C., and Moser, T. (2014). Bassoon-disruption slows vesicle replenishment and induces homeostatic plasticity at a CNS synapse. EMBO J 33, 512-527.

Meyer, A.C., Neher, E., and Schneggenburger, R. (2001). Estimation of quantal size and number of functional active zones at the calyx of Held synapse by nonstationary EPSC variance analysis. J Neurosci 21, 7889-7900.

Mowery, T.M., Caras, M.L., Hassan, S.I., Wang, D.J., Dimidschstein, J., Fishell, G., and Sanes, D.H. (2019). Preserving Inhibition during Developmental Hearing Loss Rescues Auditory Learning and Perception. J Neurosci 39, 8347-8361.

Ngodup, T., Goetz, J.A., McGuire, B.C., Sun, W., Lauer, A.M., and Xu-Friedman, M.A. (2015). Activitydependent, homeostatic regulation of neurotransmitter release from auditory nerve fibers. Proc Natl Acad Sci U S A 112, 6479-6484.

Nicol, M.J., and Walmsley, B. (2002). Ultrastructural basis of synaptic transmission between endbulbs of Held and bushy cells in the rat cochlear nucleus. J Physiol 539, 713-723. 
Oertel, D. (1999). The role of timing in the brain stem auditory nuclei of vertebrates. Annu Rev Physiol 61, 497-519.

Oleskevich, S., Youssoufian, M., and Walmsley, B. (2004). Presynaptic plasticity at two giant auditory synapses in normal and deaf mice. J Physiol 560, 709-719.

Pliss, L., Yang, H., and Xu-Friedman, M.A. (2009). Context-dependent effects of NMDA receptors on precise timing information at the endbulb of Held in the cochlear nucleus. J Neurophysiol 102, 26272637.

Prange, O., and Murphy, T.H. (1999). Correlation of miniature synaptic activity and evoked release probability in cultures of cortical neurons. J Neurosci 19, 6427-6438.

Rubio, M.E. (2020). Auditory brainstem development and plasticity. Curr Opin Physiol 18, 7-10.

Ryugo, D.K., and Fekete, D.M. (1982). Morphology of primary axosomatic endings in the anteroventral cochlear nucleus of the cat: a study of the endbulbs of Held. J Comp Neurol 210, 239-257.

Ryugo, D.K., and Sento, S. (1991). Synaptic connections of the auditory nerve in cats: relationship between endbulbs of held and spherical bushy cells. J Comp Neurol 305, 35-48.

Sanes, D.H., and Bao, S. (2009). Tuning up the developing auditory CNS. Curr Opin Neurobiol 19, 188199.

Shore, S.E., and Wu, C. (2019). Mechanisms of noise-induced tinnitus: Insights from cellular studies. Neuron 103, 8-20.

Silver, R.A. (2003). Estimation of nonuniform quantal parameters with multiple-probability fluctuation analysis: theory, application and limitations. J Neurosci Methods 130, 127-141.

Spirou, G.A., Rager, J., and Manis, P.B. (2005). Convergence of auditory-nerve fiber projections onto globular bushy cells. Neuroscience 136, 843-863.

Torrado Pacheco, A., Bottorff, J., Gao, Y., and Turrigiano, G.G. (2021). Sleep promotes downward firing rate homeostasis. Neuron 109, 530-544 e536.

Turrigiano, G. (2012). Homeostatic synaptic plasticity: local and global mechanisms for stabilizing neuronal function. Cold Spring Harb Perspect Biol 4, a005736.

Turrigiano, G.G., Leslie, K.R., Desai, N.S., Rutherford, L.C., and Nelson, S.B. (1998). Activity-dependent scaling of quantal amplitude in neocortical neurons. Nature 391, 892-896.

Walmsley, B., Berntson, A., Leao, R.N., and Fyffe, R.E. (2006). Activity-dependent regulation of synaptic strength and neuronal excitability in central auditory pathways. J Physiol 572, 313-321.

Wang, Y., and Manis, P.B. (2008). Short-term synaptic depression and recovery at the mature mammalian endbulb of Held synapse in mice. J Neurophysiol 100, 1255-1264.

Whitton, J.P., and Polley, D.B. (2011). Evaluating the perceptual and pathophysiological consequences of auditory deprivation in early postnatal life: a comparison of basic and clinical studies. J Assoc Res Otolaryngol 12, 535-547.

Wierenga, C.J., Walsh, M.F., and Turrigiano, G.G. (2006). Temporal regulation of the expression locus of homeostatic plasticity. J Neurophysiol 96, 2127-2133.

Wu, C.H., Ramos, R., Katz, D.B., and Turrigiano, G.G. (2021). Homeostatic synaptic scaling establishes the specificity of an associative memory. Curr Biol 31, 2274-2285 e2275.

Xu-Friedman, M.A., and Regehr, W.G. (2004). Structural contributions to short-term synaptic plasticity. Physiol Rev 84, 69-85.

Yang, H., and Xu-Friedman, M.A. (2009). Impact of synaptic depression on spike timing at the endbulb of Held. J Neurophysiol 102, 1699-1710.

Zhang-Hooks, Y., Agarwal, A., Mishina, M., and Bergles, D.E. (2016). NMDA Receptors Enhance Spontaneous Activity and Promote Neuronal Survival in the Developing Cochlea. Neuron 89, 337350. 
Zhou, X., Wang, L., Hasegawa, H., Amin, P., Han, B.X., Kaneko, S., He, Y., and Wang, F. (2010). Deletion of PIK3C3/Vps34 in sensory neurons causes rapid neurodegeneration by disrupting the endosomal but not the autophagic pathway. Proc Natl Acad Sci U S A 107, 9424-9429.

Zhuang, X., Sun, W., and Xu-Friedman, M.A. (2017). Changes in properties of auditory nerve synapses following conductive hearing loss. J Neurosci 37, 323-332.

Zhuang, X., Wong, N.F., Sun, W., and Xu-Friedman, M.A. (2020). Mechanisms and functional consequences of presynaptic homeostatic plasticity at auditory nerve synapses. J Neurosci 40, 68966909. 


\section{Figure Legends}

Figure 1. Speed of activity-dependent changes in $\mathrm{EPSC}_{1}$ amplitude and PPR at auditory nerve synapses.

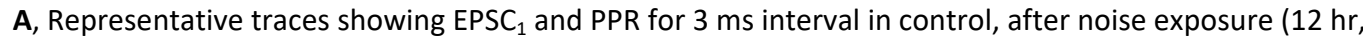
$18 \mathrm{hr}, 1 \mathrm{~d}, 2 \mathrm{~d}, 7 \mathrm{~d})$, and after ear ligation (1 d, $2 \mathrm{~d}$, and $7 \mathrm{~d}$ ). Manipulations were started at P21. B, EPSC 1

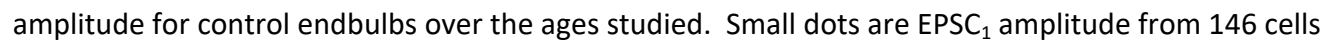
from 39 mice, and open circles are averages for the age or exposure ranges demarcated by different shading. There were no significant differences between groups ( $p=0.8$, Kruskal-Wallis test). Line is regression of individual data. C, Effects of noise exposure (195 cells, 50 mice, red) and ear ligation (124 cells, 33 mice, blue) on $\mathrm{EPSC}_{1}$ amplitude. Lines are fits to individual data using segmented regression (see Results). A Kruskal-Wallis test indicated significant differences between exposure groups $(p>$ $0.001)$, and asterisks mark points that were significantly different from control $(p<0.05$, AndersonDarling many-to-one post-hoc test). D, PPR for control endbulbs over the ages studied. There were no significant differences between age groups ( $p=0.13$, ANOVA). Line is regression of individual data. E, Effects of noise exposure (red) or ear ligation (blue) on PPR. Lines are fits of individual data to the exponential decay function (see Results). ANOVA indicated significant differences between groups ( $p<$ 0.001), and asterisks mark points that differed significantly from control $(p<0.05$, Tamhane-Dunnett's test). Markers throughout are mean \pm SEM.

Figure 2. Changes in quantal size and frequency after noise exposure or ear ligation. A, Representative traces of spontaneous synaptic activity for auditory nerve synapses from control (left, black), noiseexposed (center, red), and ear-ligated (right, blue) mice. B, C, Amplitude (B) and frequency (C) of mEPSCs in control mice. Small markers are individual experiments, and open circles are averages for age groups demarcated by shading. Kruskal-Wallis tests showed no significant differences between groups in 
mEPSC amplitude or frequency (both $p>0.5$ ). Lines are regressions to individual data. D, E, Amplitude (D) and frequency (E) of mEPSCs after noise exposure (red) or ear ligation (blue). Small dots are individual experiments, and open circles are averages for the exposure durations demarcated by shading. Lines in E are fits to individual data using segmented regression (see Results). There were no significant effects of noise exposure or ear ligation on mEPSC amplitude (both $p>0.15$, Kruskal-Wallis), nor mEPSC frequency after noise exposure $(p=0.53)$, but mEPSC frequency decreased significantly following ear ligation $(p=0.02)$, and asterisks mark points that differed significantly from control $(p<$ 0.05 , Anderson-Darling many-to-one test). Black line and grey shaded area represent pooled average \pm SEM from control cells.

Figure 3. Activity-dependent changes assessed using mean-variance analysis. A, Representative experiment recording from a $\mathrm{BC}$ of a control animal. Markers are $\mathrm{EPSC}_{1}$ amplitudes measured over the course of an experiment in 3 different external calcium concentrations $\left(\mathrm{Ca}_{e} ; 1,1.5\right.$, or $\left.3 \mathrm{mM}\right)$. B, C, Representative experiments with BCs from animals noise-exposed for $1 \mathrm{~d}$ (B) or $7 d$ (C). D, Mean and variance from control experiment in $\mathbf{A}$ (closed black circles), noise-exposed for $1 \mathrm{~d}$ in $\mathbf{B}$ (open red circles), and noise-exposed for $\mathbf{7} \mathrm{d}$ in $\mathbf{C}$ (closed red circles). Lines are fits to the mean-variance relationship (see Results) to estimate $N, P_{r}$, and $Q . E, F$, Representative recordings made from $\mathrm{BCs}$ in animals ear-ligated for 2 (E) or $7 \mathrm{~d}$ (F). G, Mean and variance from control experiment in A (closed black circles), ear-ligated $2 \mathrm{~d}$ in $\mathbf{E}$ (open blue circles), and ear-ligated $7 \mathrm{~d}$ in $\mathbf{F}$ (closed blue circles). Lines are fits to the mean-variance relationship (see Results). $\mathbf{H}-\mathbf{J}$. Histograms for $N(\mathbf{H}), Q(\mathbf{I})$, and $\mathrm{P}_{\mathrm{r}}(\mathrm{J})$ for control, noise-exposed 1 or $7 d$, and ear-ligated 2 or $7 d$. Dots are individual data. Bars are mean \pm SEM. Asterisks $\left({ }^{*}\right)$ denote significant difference from control $(p<0.05$, Kruskal-Wallis followed by AndersonDarling many-to-one test). 
Figure 4. Structural changes in endbulbs after noise exposure and ear ligation. A, Optical section from the cochlear nucleus of an AVIL-YFP mouse immunostained for VGluT1. YFP labelling is shown in cyan, and VGluT1 in yellow. B, Traces of four different endbulbs (red, magenta, blue, black) around the BC in A. Optical sections were sampled every $0.3 \mu \mathrm{m}$, with every third section shown here. The tracings at the left of the third row (asterisk) correspond to the images in A. C, Synaptic volumes from P24 animals in control conditions, noise-exposed for $3 \mathrm{~d}$, ear-ligated for $3 \mathrm{~d}$, P27 control animals, noise-exposed for 7 $\mathrm{d}$, and ear-ligated for $7 \mathrm{~d}$. Dots are individual synaptic volumes, and bars are averages \pm SEM. Asterisks $\left(^{*}\right)$ denote significant difference from age-matched controls $(p<0.05$, Kruskal-Wallis followed by Anderson-Darling all-pairs test).

Figure 5. Efficacy of ear-plugging vs. ear-ligation. A. Representative ABRs from control, plugged, and ligated ears. Arrowheads mark threshold. B. ABR threshold for control, plugged, and ligated ears. C, PPR recorded from BCs in ear-plugged animals. Small triangles are PPRs from individual cells, and open red triangles are averages. Average PPRs for ear-ligated cells are duplicated from Fig. 1 for comparison (open blue circles). The black line and dark grey bar indicate control mean \pm SEM. PPR after ear-plugging did not differ significantly from ear-ligating at any time point ( $p>0.5$, each comparison).

Figure 6. Recovery of PPR after noise exposure and ear-plugging. A. PPR after $0,0.25,0.5$, 1 , or $1.5 \mathrm{~d}$ recovery in quiet conditions, following noise exposure for $3 \mathrm{~d}$ (red) or $10 \mathrm{~d}$ (purple). Dots are individual data, and open circles are averages. B. PPR after $3 \mathrm{~d}$ of ear-plugging. Black line and grey bar in A and B represent the control mean $\pm \operatorname{SEM}$. Asterisks $\left({ }^{*}\right)$ denote points significantly different from control $(p<$ 0.05, Kruskal-Wallis followed by Anderson-Darling many-to-one test). 
725 Figure 7. Effects of periodic noise exposure. A, Treatment paradigm. Grey bars represent times that the noise was on each day for a week. On day 7, slices were prepared for electrophysiology immediately after ending noise exposure. B, C, PPR (B) and EPSC ${ }_{1}$ amplitude (C) following $7 \mathrm{~d}$ of noise exposure for 0 , $4,8,12,24 \mathrm{hr} / \mathrm{d}$ (15 to 27 cells per point). Small dots indicate individual data, and open circles are averages. Asterisks $\left({ }^{*}\right)$ denote PPRs significantly greater than $0 \mathrm{hr} / \mathrm{d}(p<0.05$, Kruskal-Wallis followed by Anderson-Darling many-to-one test). EPSC $_{1}$ did not change significantly ( $p=0.23$, Kruskal-Wallis).

Figure 8. Graphical summary of synaptic changes. Diagram shows an auditory nerve fiber (blue) contacting a bushy cell (black outline). Release sites are indicated as orange dots. Noise exposure leads to decreased $P_{\mathrm{r}}$ (yellow), followed by structural changes and addition of release sites. Conductive hearing loss ( $\mathrm{CHL}$ ) induces rapid inactivation of release sites (grey), followed by an increase in $P_{\mathrm{r}}$ (red), and then by structural changes 
Ai Control ii Noise-exposed

iii Ear-ligated

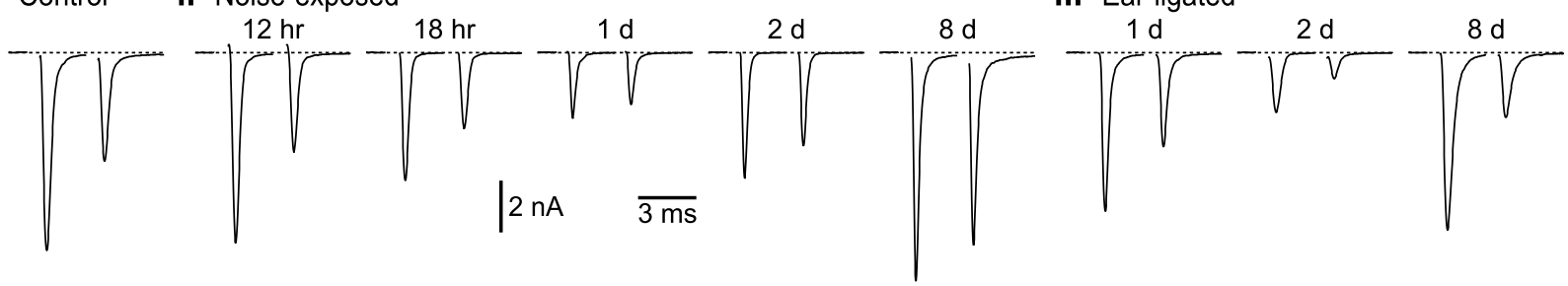

B

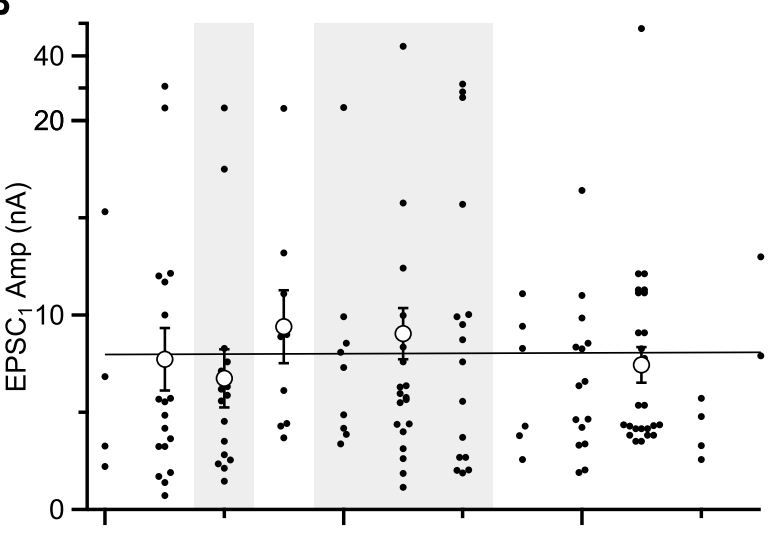

C
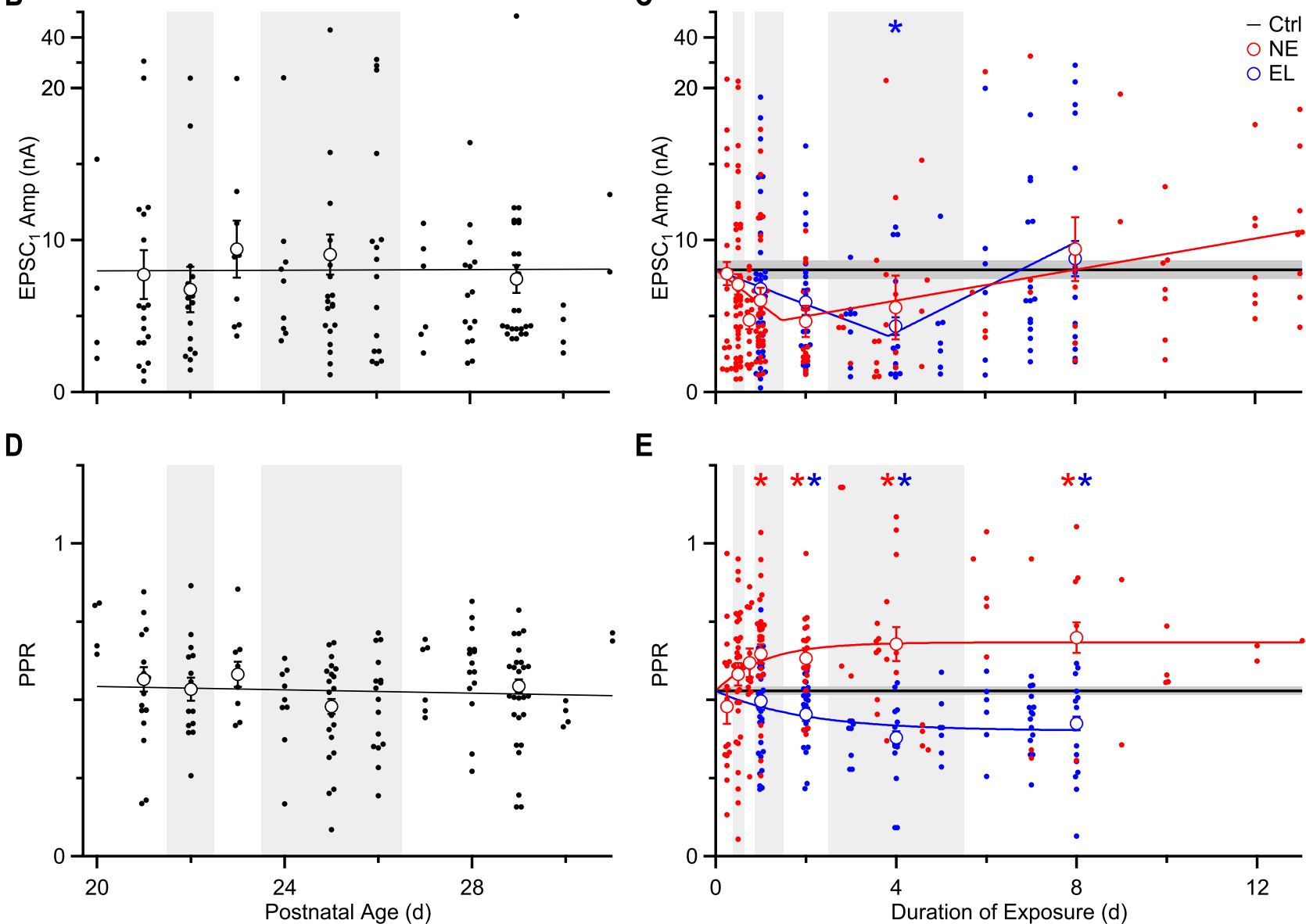

E

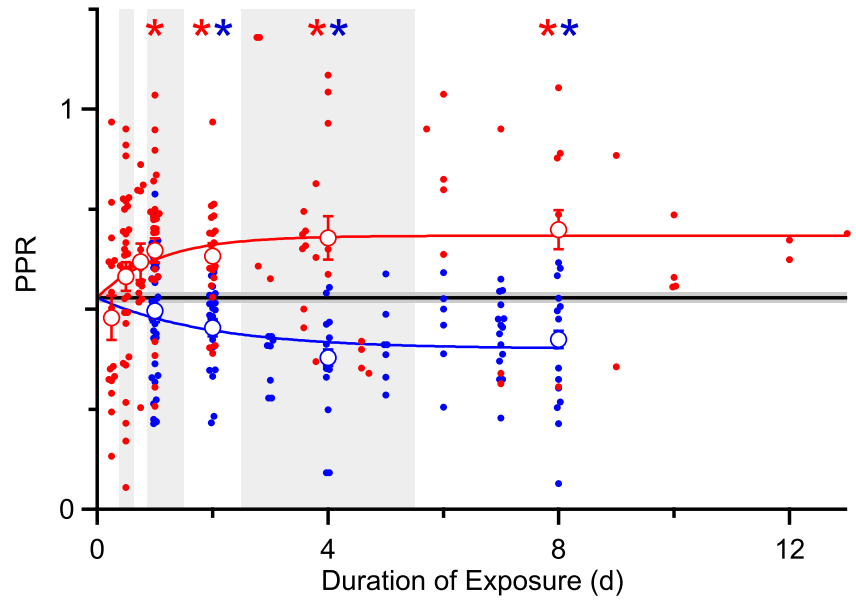

Figure 1 

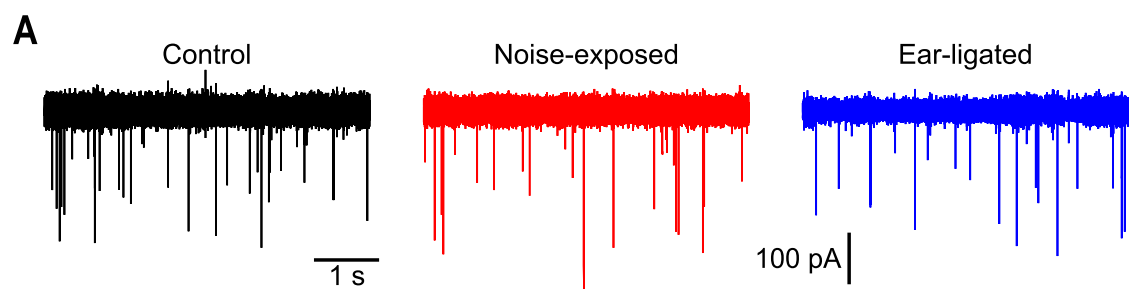

B

D
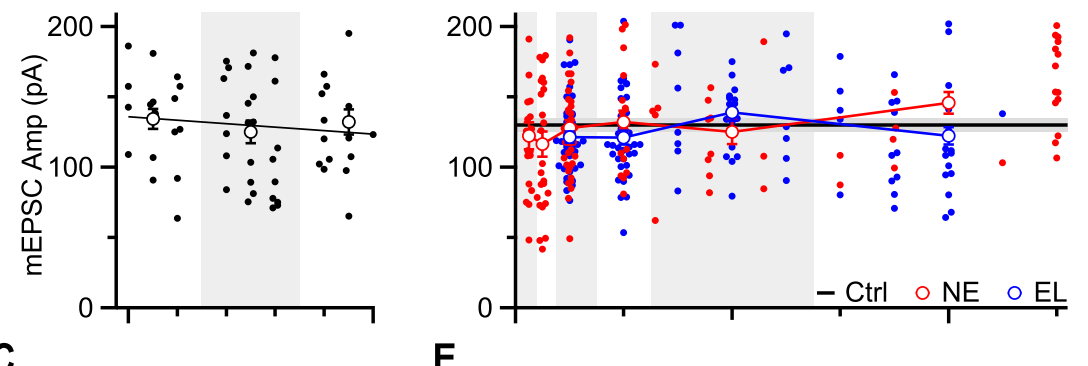

C
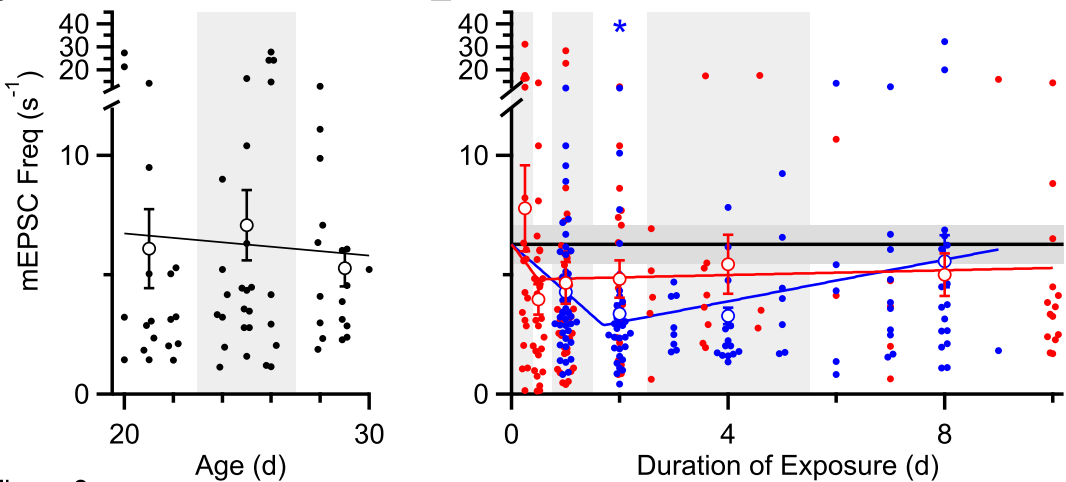

Figure 2 
A Control
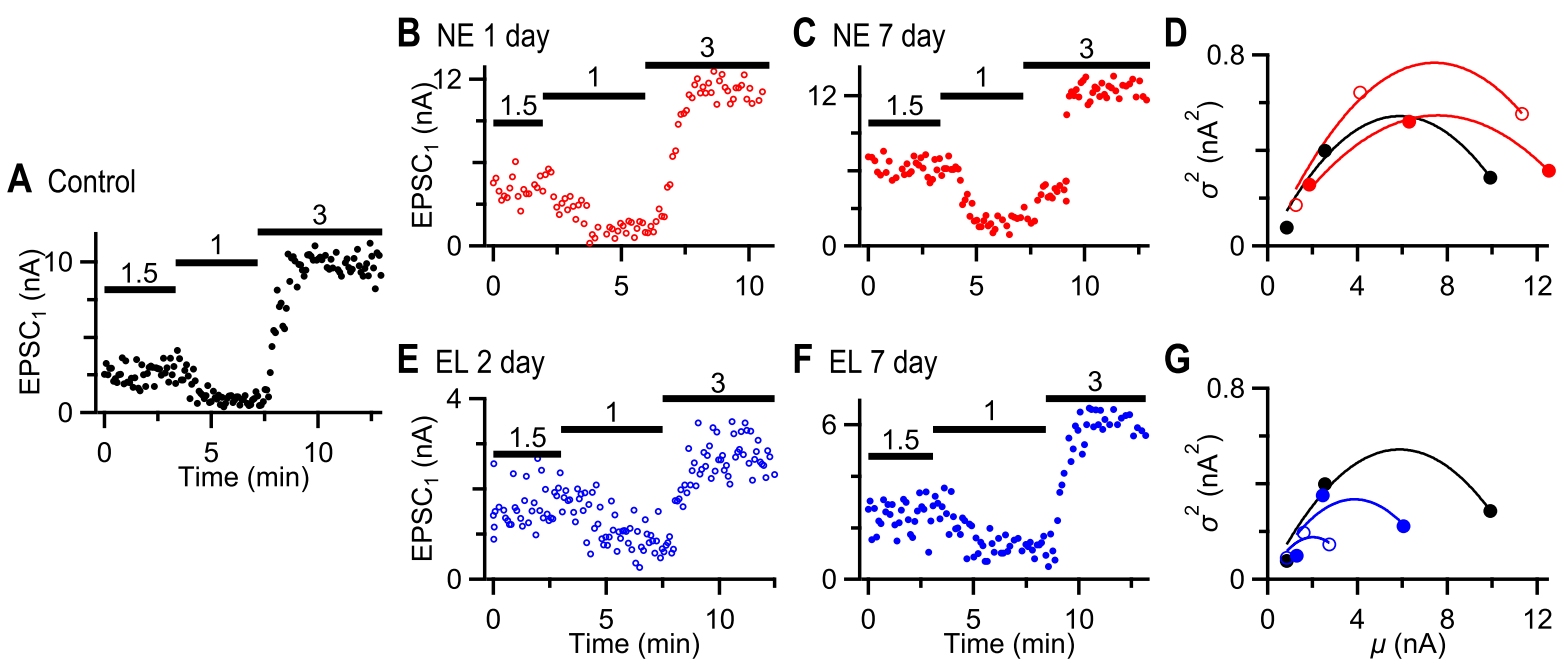

F EL 7 day G
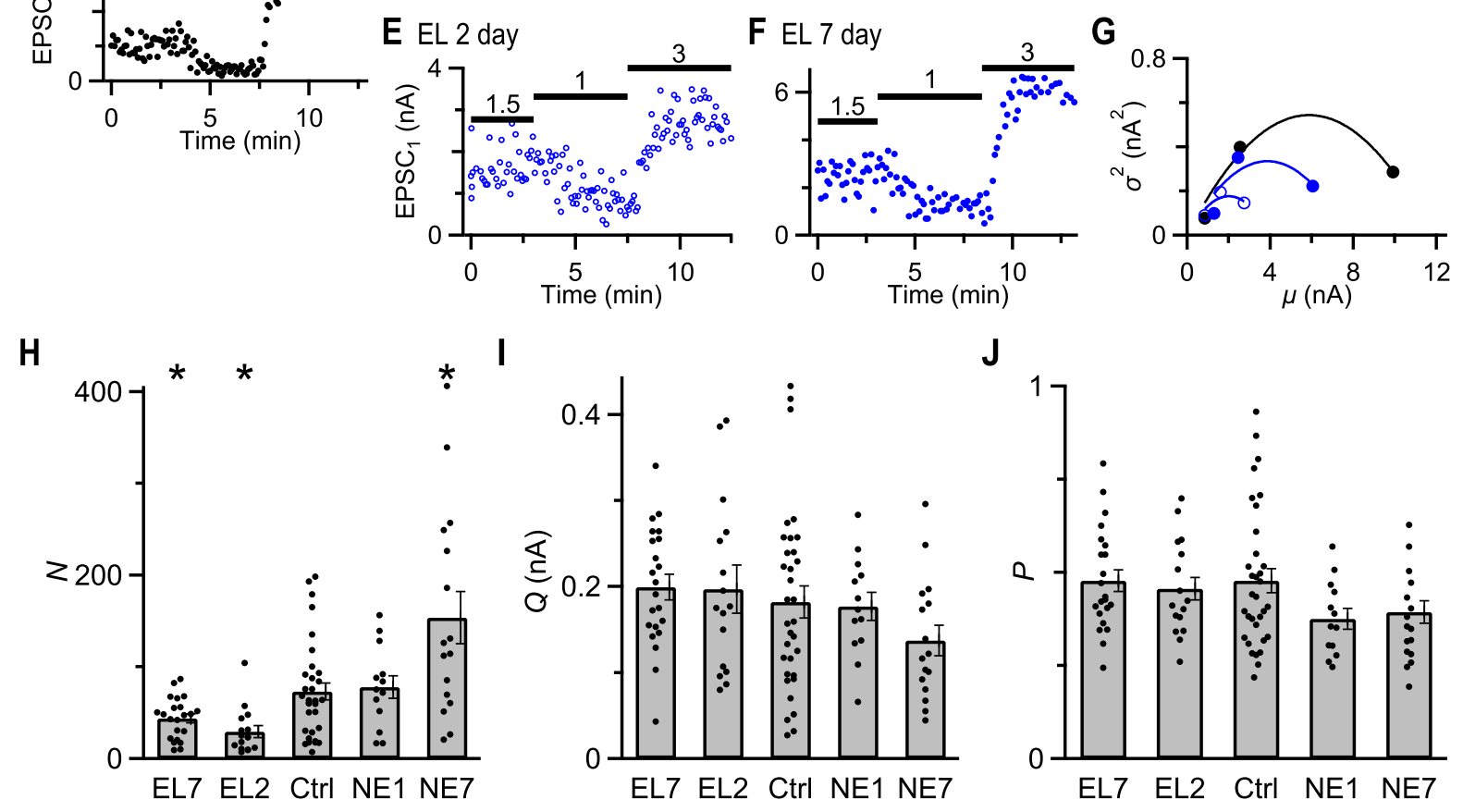

Figure 3 

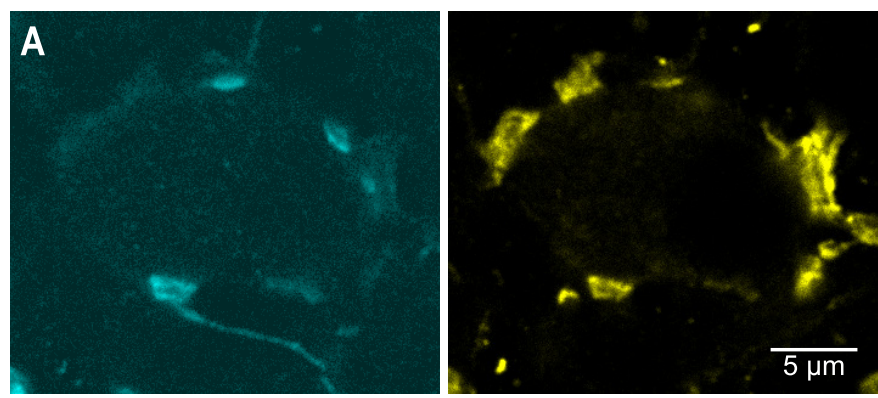

B
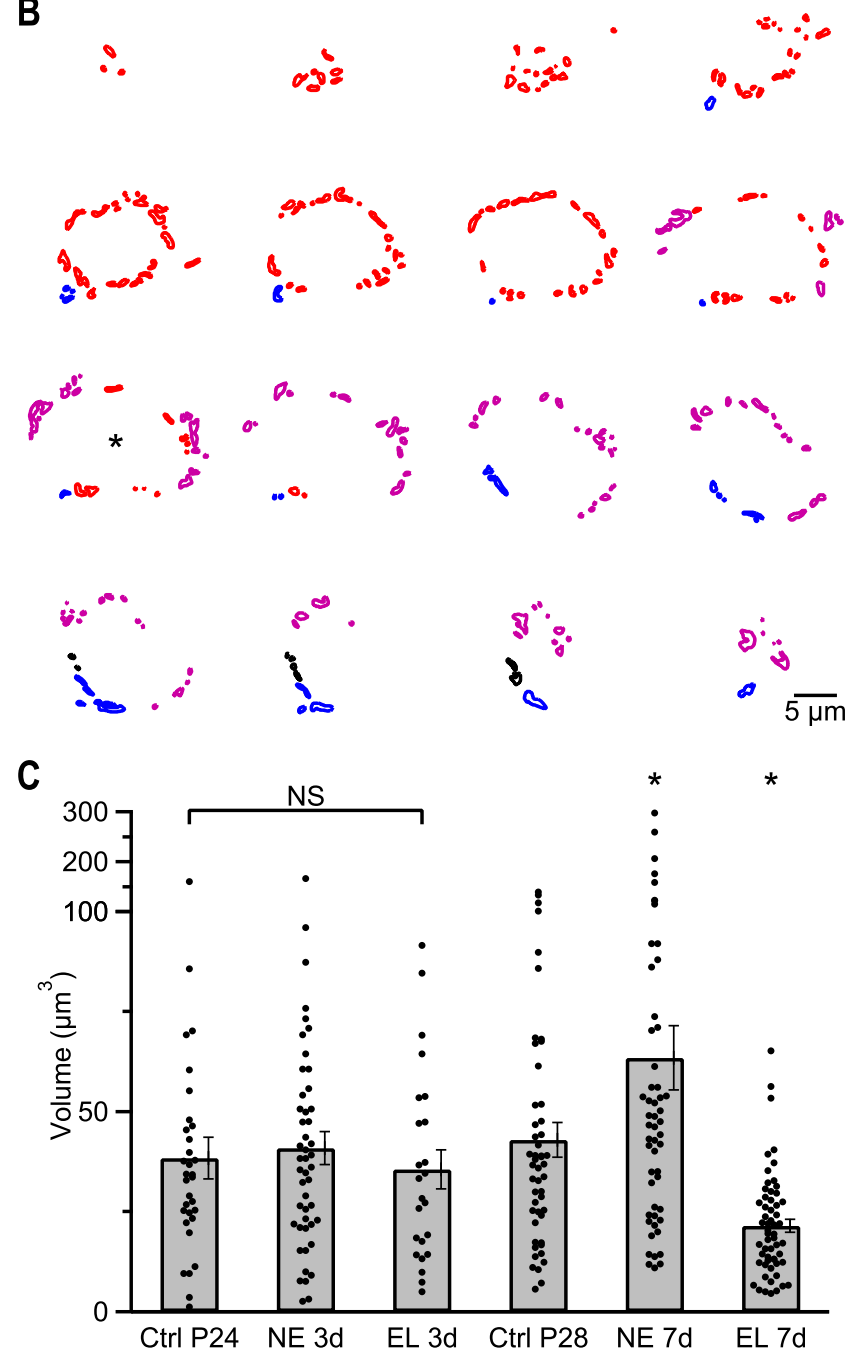

Figure 4 


\section{A}

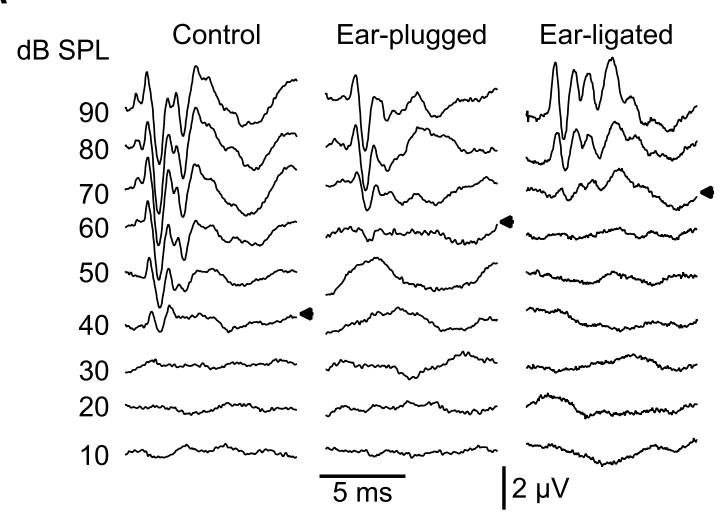

B

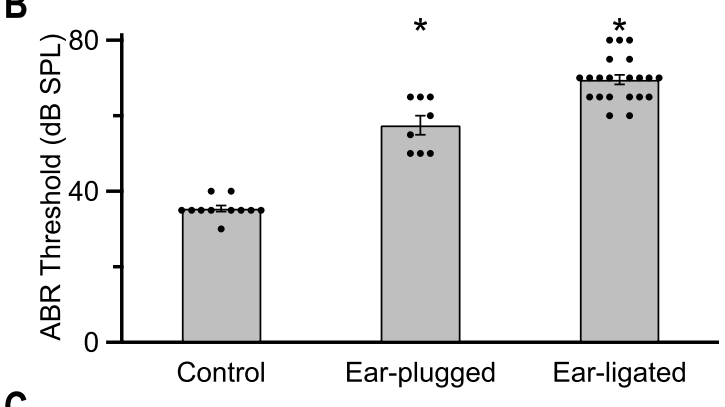

C

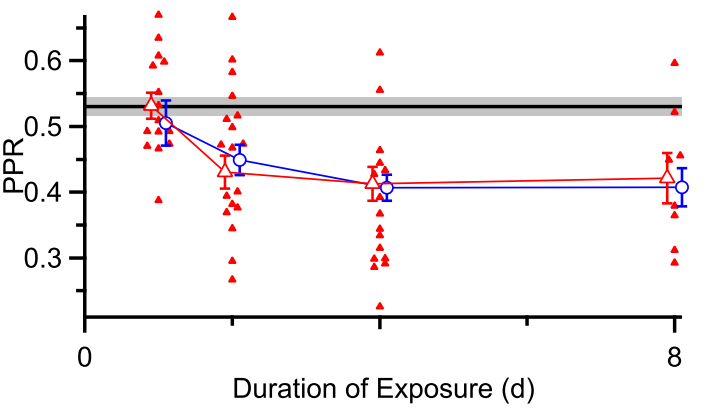

Figure 5 

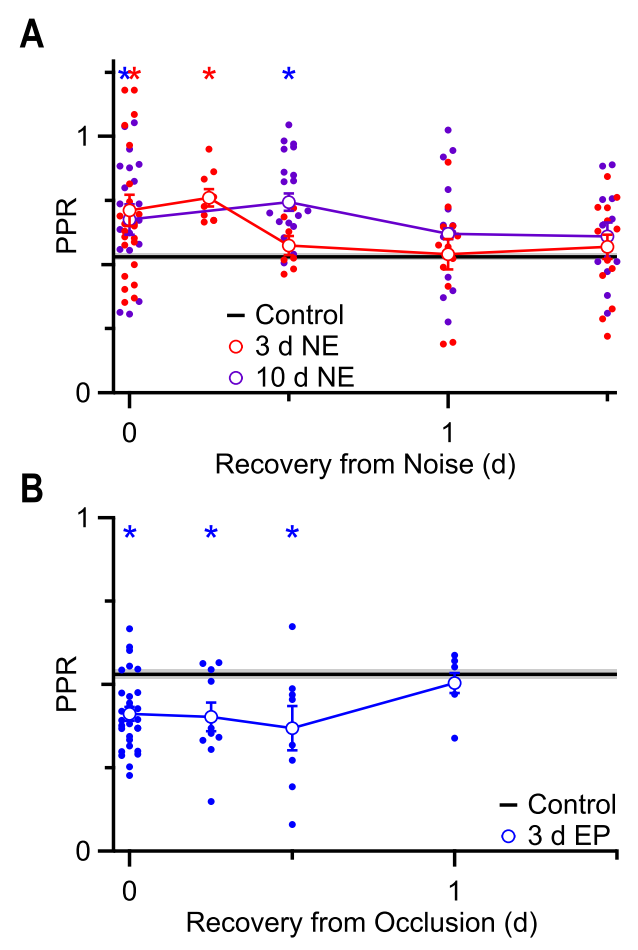

Figure 6 


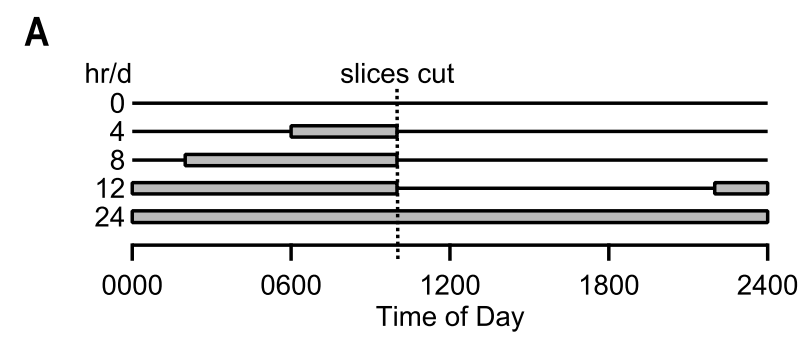

\section{B}

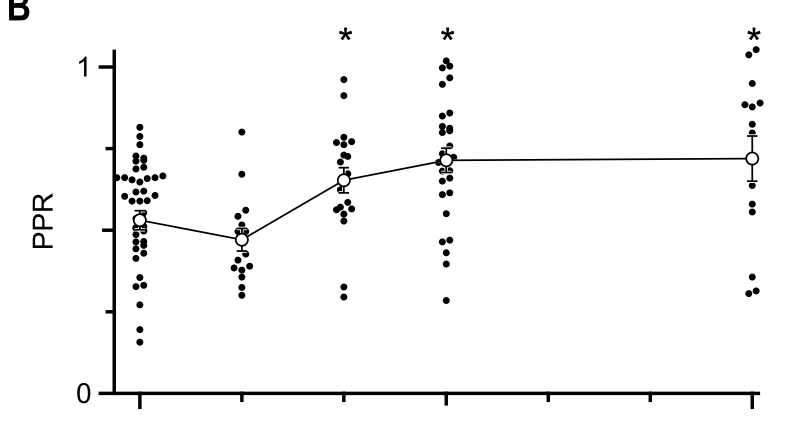

C

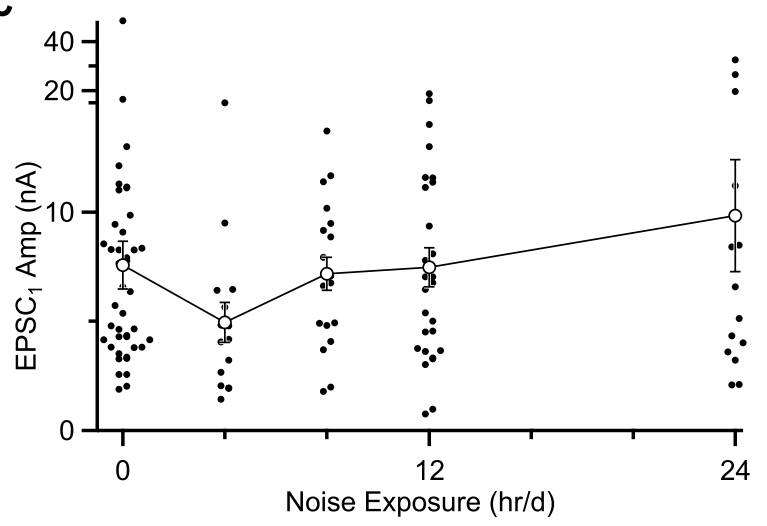

Figure 7 


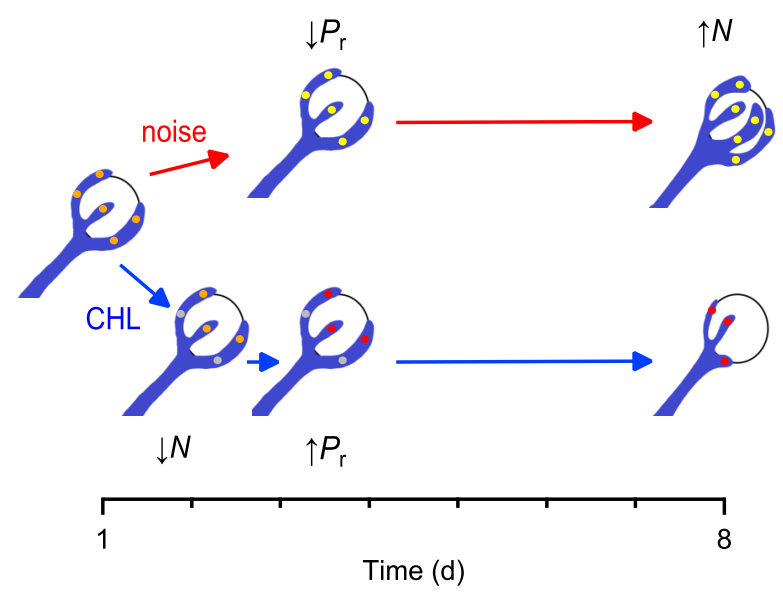

Figure 8 